\title{
Trypanosome morphogenesis involves recruitment of a pleckstrin homology domain protein by an orphan kinesin to the microtubule quartet
}

\author{
Corinna Benz ${ }^{1}$, Nora Müller ${ }^{2}$, Sabine Kaltenbrunner ${ }^{1,2,{ }^{\dagger}}$, Hana Váchová ${ }^{3}$, Marie Vancová ${ }^{1,2}$, \\ Julius Lukeš ${ }^{1,2}$, Vladimír Varga ${ }^{3}$, Hassan Hashimi ${ }^{1,2, *}$ \\ ${ }^{1}$ Institute of Parasitology, Biology Center, Czech Academy of Sciences, České Budějovice, Czechia \\ ${ }^{2}$ Faculty of Science, University of South Bohemia, České Budějovice, Czechia \\ ${ }^{3}$ Laboratory of Cell Motility, Institute of Molecular Genetics of the Czech Academy of Sciences, \\ Prague, Czechia \\ ${ }^{\dagger}$ Current address: Johannes Kepler University, Medical Faculty, Linz, Austria \\ *Corresponding author: hassan@paru.cas.cz
}

Running title: TbKifX2 and TbPH1 association with the trypanosomal microtubule quartet

\begin{abstract}
Kinesins are motor proteins found in all eukaryotic lineages that move along microtubule tracks to mediate numerous cellular processes such as mitosis and intracellular transport of cargo. In trypanosomatids, the kinesin superfamily has undergone a prominent expansion, giving these protists one of the most diverse kinesin repertoires including two trypanosomatid-restricted groups. Here, we characterize in Trypanosoma brucei TbKifX2, a hitherto orphaned trypanosomatid-specific kinesin. TbKifX2 tightly interacts with TbPH1, a kinesin-like protein with an inactive motor domain, a rare instance of a kinesin interacting with a protein bearing a catalytically dead kinesin motor domain. TbKifX2 recruits TbPH1 to the microtubule quartet (MtQ), a characteristic but poorly understood cytoskeletal structure that is part of the multipartite flagellum attachment zone (FAZ) and extends from the basal body to the anterior of the cell body. The proximal proteome of TbPH1 is comprised of four proteins that localize to the $F A Z$, consistent with the notion that the TbKifX2/TbPH1 complex bind the MtQ, a FAZ component. Simultaneous ablation of TbKifX2/TbPH1 leads to formation of prominent protrusions from the cell posterior. Thus, these two trypanosomatid-restricted proteins appear to contribute to morphogenesis in T. brucei. Furthermore, TbKifX2 is the first motor protein to be localized to the MtQ.
\end{abstract}

Keywords: Trypanosoma, kinesin, cytoskeleton, microtubules, microtubule quartet, morphogenesis 


\section{INTRODUCTION}

The vermiform morphology of the unicellular parasite Trypanosoma brucei that causes African trypanosomiasis in humans and nagana in cattle is defined by a subpellicular array of microtubules (MTs) (Robinson et al., 1995; Gull, 1999; Wheeler et al., 2013). These MTs are cross-linked to each other and the plasma membrane via regularly spaced fibrils (Sherwin et al., 1987). A high order is maintained within the corset with the MT plus ends converging at the parasite's posterior end and the minus ends located at the anterior of the cell (Robinson et al., 1995).

The only place where the continuity of the T. brucei MT array is interrupted is at the flagellar pocket, the deep invagination where the flagellum exits the cell body and the only place where endo- and exocytoses occur (Field and Carrington, 2009). The opening of the flagellar pocket is encircled by a collar, which influences the overall shape of this cavity. Distal to the collar, the so-called hook complex covers the flagellum as it exits the flagellar pocket, with two lateral arms also flanking the flagellum attachment zone (FAZ) filament and the MT quartet (MtQ) inside the cell (Albisetti et al., 2017). The FAZ filament and MtQ are among the interconnected fibres, filaments and junctional complexes of the multipartite FAZ (Lacomble et al., 2009), which together form a lateral attachment for the flagellum as it follows a helical path along the cell body, connecting the flagellar skeleton to the cytoskeleton through both the flagellar and plasma membranes (Sunter and Gull, 2016). The $\mathrm{MtQ}$ originates close to the basal bodies, wraps itself around the flagellar pocket and interdigitates within the MT corset next to the FAZ filament. The orientation of MTs in the MtQ is antiparallel to the one found within the MT corset, thus their minus ends are proximal to the basal bodies (Robinson et al., 1995).

The trypanosome MT corset is exceptionally stable and only reorganised during cell division and life cycle transitions (Sinclair and de Graffenried, 2019). Cytoskeletal structures (MtQ, MT corset, flagellum, basal bodies, which anchor the flagella with in the cell, and FAZ) need to be duplicated and faithfully segregated during the cell division cycle, just like other single-copy organelles. In addition, this has to be coordinated with replication and division of the nucleus and the single mitochondrial DNA network termed the kinetoplast, which is located on the opposite side of the basal bodies relative to the flagellum (Robinson et al., 1995; Wheeler et al., 2019).

Basal body duplication and segregation are the first visible steps in the cell division cycle and essential for subsequent cytokinesis (Woodward and Gull, 1990). The new MtQ starts growing just prior to basal body maturation and once the new flagellum has grown enough to invade the flagellar pocket, morphogenetic changes result in two separate pockets enveloping both the new and old flagella (Lacomble et al., 2010). Once the new flagellum has been nucleated and elongated, new MTs are integrated into the array between the old and new flagella, thereby increasing the overall width of the cell (Wheeler et al., 2013).

With its antiparallel orientation, the MtQ together with the FAZ filament create an asymmetric seam within the MT corset, which works as a 'cellular ruler' and helps to determine the site of future furrow ingression during cytokinesis (Sunter and Gull, 2016). Any insults to the integrity of these structures result in cytokinesis defects and it is thus tempting to envision the MtQ as a potential specialised 'highway' in charge of transport and delivery of cargo to the site of important cytokinesis events. Furthermore, the endplasmic reticulum associates with parts of the $M t Q$, although the importance of this association remains mysterious. The first protein localized to this structure, TbSpef1, is found at the proximal end of the MtQ, which wraps around the flagellar pocket between basal bodies and the flagellar pocket collar (Gheiratmand et al., 2013). Its depletion causes problems with the biogenesis of the MtQ and associated structures as well as motility defects. The minus end 
of the MtQ MTs is anchored to the basal bodies by a protein named TbSAF1, found in close proximity to TbSpef1 but localized between the pro and mature basal bodies (Dong et al., 2020). TbSAF1 was found in a proximal proteomics screen of proteins adjoining to and/or directly interacting with TbSpef1, which found three additional proteins that localize to the MtQ between the basal body and flagellar pocket collar (Dong et al., 2020). However, no motor proteins that localise to the MtQ, and which may potentially bring cargo to the cytokinesis site, have thus far been identified.

Kinesins are well-studied motor proteins that regulate MT dynamics, organize MT networks, and transport cargo along MTs. Transporting kinesins can form homo- and heterodimers and consist of a head region containing the kinesin motor domain, which is responsible for ATP hydrolysis and MT binding, and a tail region important for dimerization with a kinesin/kinesin-like partner and cargo binding (Hirokawa and Noda, 2008). In trypanosomatid genomes, kinesins and kinesin-like proteins constitute one of the largest protein superfamilies (Berriman et al., 2005; El-Sayed et al., 2005; Ivens et al., 2005). To date, 47 genes encoding high-likelihood kinesins have been identified in the T. brucei genome (Wickstead and Gull, 2006; Wickstead et al., 2010b). Moreover, there is a similar number of kinesin-related proteins, which did not make the threshold due to sequence variance (Berriman et al., 2005). Interestingly, numerous kinesins are members of two major clades named X-1 and X-2 that are restricted to the trypanosomatid lineage (Wickstead and Gull, 2006; Wickstead et al., 2010b). Why the kinesin repertoire has expanded so prominently in trypanosomatids remains mysterious.

Hitherto studied kinesins of $T$. brucei have been shown to be important for various processes occurring in different cellular compartments. KinA and KinB are involved in cell cycle progression and localise to the central spindle during mitosis (Li et al., 2008) while TbKif13-1 localizes either to the nucleus or the mitotic spindle, where it meditates chromosome segregation during mitosis (Wickstead et al., 2010a). KinC and KinD are distributed throughout the cytoskeleton, where they are involved in subpellicular MT organization, basal body segregation and cytokinesis (Hu et al., 2012; Wei et al., 2013).

Some kinesins are associated with the flagellum and adjacent FAZ. KIN2A and KIN2B are kinesins involved in intraflagellar transport, a process that directly affects flagellar assembly and in turn affects cell motility and cytokinesis (Aslett et al., 2009; Bertiaux et al., 2020). The orphan kinesin KINE predominantly localises to the flagellar tip and is required for elongation of the new FAZ (An and Li, 2018). Another orphan kinesin named KLIF initially localises to the tip of the new, elongating FAZ and associates with the old FAZ as the cytokinetic furrow ingresses towards the posterior end, thus mediating the final stages of cytokinesis (Hilton et al., 2018). Other kinesins localising to specific cytoskeletal structures include FCP2/TbKinX1 and FCP4/TbKin15, which are found at the flagella connector ( $\mathrm{FC}$ ), a trypanosome-specific structure that connects the outgrowing new flagellum to the old one (Varga et al., 2017). Interestingly, FCP2/TbKinX1 belongs to kinesin clade X-1, one of the two trypanosomatid-restricted kinesin families (Wickstead and Gull, 2006; Wickstead et al., 2010b).

Here we present data on the localisation and function of two members of the kinesin superfamily, TbKifX 2 and TbPH1, with the former protein belonging to clade X-2. Functional characterization and the unique localization of these kinesins further expands our knowledge on how these diverse and dexterous proteins affect the biology of these extremely diverse and successful parasites.

\section{RESULTS}

$\mathrm{TbPH} 1$ is a kinesin-like prote in that fractionates with the $T$. brucei cytoskeleton 
126

127

128

129

130

131

132

133

134

135

136

137

138

139

140

141

142

143

144

145

146

147

148

149

150

151
TbPH1 (Tb927.3.2490) is a $110 \mathrm{kDa}$ protein named after a C-terminal pleckstrin homology (PH) domain, which is followed by a proximate homeodomain-like (HDL) fold and preceded by a coiled coil (CC) domain (Fig. 1). The protein undergoes post-translational modifications, with phosphorylation of a serine at the start of the HDL (Urbaniak et al., 2012) and a methylarginine in the middle of the primary structure (Lott et al., 2013). While TbPH1 has an N-terminal kinesin motor domain, two substitutions of highly conserved amino acids within the Walker A motif (G93P and T/S95R) likely ablate the ATP hydrolase activity. Thus, TbPH1 is unlikely to be a bona fide kinesin motor protein.

TbPH1 also belongs to the 2000 proteins found in the granule-enriched fraction (containing cellular aggregates, nuclei, kinetoplasts and flagella as well as associated cytoskeletal structures) obtained by 'MT sieving', a method originally conceived to purify stress granules from T. brucei (Fritz et al., 2015). In brief (see S1 Fig. for 'MT sieving' pipeline), cells are lysed by non-ionic detergent in low ionic strength buffer, which maintains the cytoskeleton, including the MT corset that in turn cages predominantly detergent insoluble cellular structures with at least one dimension $>20-30 \mathrm{~nm}$. The MT corset is then disrupted by $300 \mathrm{~m} \mathrm{M} \mathrm{NaCl}$ to release these elements for subsequent analysis.

To verify TbPH1's apparent association with cytoskeletal fractions, we subjected a T. brucei cell line in which the endogenous $\mathrm{TbPH} 1$ open reading frame was appended with a C-terminal V5 tag (Dean et al. , 2017) to cell fractionation by a procedure identical to 'MT sieving'. The cell equivalents of the ensuing fractions were inspected for the presence of TbPH1-V5 and SCD6, a stress granule marker that served as a control for this method (Fig. 2A). SCD6 was mostly found in the soluble fractions as previously reported for unstressed T. brucei (Fritz et al., 2015), with a distribution across the analysed fractions very distinct from that of TbPH1-V5. TbPH1-V5 was well retained in all cytoskeletal fractions $\mathrm{P} 1$ and $\mathrm{P} 2$, although a fraction was released in the SN1 with other soluble cytosolic proteins upon initial lysis (Fig. 2A). Importantly, an aliquot of $P 2$ fraction that was fixed on microscopic slides for indirect immunofluorescence (IFA) using an anti-V5 antibody shows that TbPH1-V5 is localized as a line extending from the DAPI-stained kinetoplast (Fig. 2B) that decreases in signal intensity distally, suggestive of a cytoskeletal localization. This was confirmed by the observation that the vast majority of TbPH1 was released into the soluble SN3 fraction after high salt disintegration of the cytoskeleton. A small amount of TbPH1-V5 was still found in the final pellet P3, which is consistent with its detection in the cohort of proteins retained by 'MT sieving' (Fritz et al., 2015). Thus, TbPH1 is a kinesin-like protein that fractionates with the trypanosomal cytoskeleton.

\section{TbPH1 strongly interacts with the trypanosomatid-restricted orphan kinesin TbKifX2}

Because kinesins tend to form dimers (Marx et al., 2009) and kinesin-like TbPH1 contains a CC domain (Fig. 1), which usually mediates protein-protein interactions (Burkhard et al., 2001), we proceeded to see if TbPH1-V5 has an interaction partner by immunoprecipitation (IP) via its Cterminal epitope tag. To enrich for soluble TbPH1-V5 and augment IP stringency, we followed the previously described fractionation technique and used fraction SN3 as the input (Fig. 3A). A mock IP control using the parental cell line without an expressed V5 epitope was performed in parallel.

After confirming immunocapture of TbPH1-V5 in the first eluate (Fig. 3A), the IP eluate from this and the mock control were resolved on a SDS PAGE gel. Sypro Ruby protein gel staining showed two prominent bands of $\sim 117 \mathrm{kDa}$ (Fig. 3B, B1), the expected size for TbPH1-V5, and of $\sim 80 \mathrm{kDa}$ (Fig. 3B, B2). Importantly, these bands were not observed in the mock control, indicating their presence is not due to unspecific binding to the magnetic beads used to immobilize the anti-V5 antibody. Mass spectrometry analysis of these two excised bands identified TbPH1 itself as expected and a previously uncharacterised kinetoplastid-specific kinesin (Tb927.9.15470) (S1 Dataset), which we call 
TbKifX2 based on a previously proposed kinesin nomenclature (Wickstead et al., 2010b). In contrast to TbPH1, TbKifX2's kinesin motor domain contains a conventional Walker A motif (Fig. 1). This motor domain is located on the $\mathrm{N}$-terminus, indicating that TbKiFX2 actively moves toward the plusend of MTs (Hirokawa et al., 2009). It also contains a CC domain and two serine phosphorylation sites (Urbaniak et al., 2012), similarly to TbPH1.

Interaction between these two proteins was further verified by tagging TbKifX2 with a C-terminal HA tag in the TbPH1-V5 cell line. Indeed, TbKifX2 mirrored the fractionation pattern of TbPH1-V5 (Fig. 3C). As before, the SN3 fraction was used as an input for TbKifX2-HA IP, which coimmunoprecipitated TbPH1-V5. Thus, we verified that TbPH1 and TbKifX2 exhibit a strong interaction that persists even in $300 \mathrm{mM} \mathrm{NaCl}$.

Whole cells expressing TbPH1-V5 and TbKifX2-HA were fixed and permeabilized prior to incubation with antibodies recognizing either epitope-tag (Figs. 3D and E). We observed that both proteins possess a considerable cell body signal that appears to be nucleus-excluded, with a prominent signal along the proximal region of the flagellum. This pattern is similar to the TrypTag localization data, which visualized mNeonGreen-tagged proteins in immobilized live cells (Dean et al., 2017). The cell body signal likely represents the cytosolic population of both proteins that was also observed in our fractionation data (Figs. 2A and $3 \mathrm{C}$ ). It should be also noted that TbPH1-V5 only also displays an increased signal on the anterior tip of the cell body (Fig. 3D, asterisks).

\section{Proximity proteomics reveals TbPH1 and TbKifX2 interactors that are associated with the flagellum attachment zone}

Since conventional IP of TbPH1-V5 under high salt conditions identified only TbKifX2 as its major interaction partner, we sought a different method to identify potential cargo and/or interactors of this putative kinesin complex. To do this, we tagged TbPH1 with a C-terminal biotin ligase 'BiolD2' (Kim et al., 2016), appended with an HA tag (Pyrih et al., 2020), to facilitate proximity-dependent biotin identification (BioID) of neighbouring proteins. First, we determined by IFA on permeabilized whole cells using anti-HA antibody that TbPH1-BiolD2-HA localizes adjacent to the kinetoplast, which was also observed for TbPH1-V5 (c.f. Figs. 2B and 4A). TbPH1-BiolD2-HA also exhibited biotinylation activity, as visualized by streptavidin-conjugated to Alexa Fluor 488 (Fig. 4A), in contrast to the parental cell line lacking BiolD2 (Fig. 4B). Thus, we confirmed that the chimeric protein is properly localized and appears to biotinylate TbPH1 itself or proximal proteins.

Purification of biotinylated proteins was performed as described elsewhere (Morriswood et al., 2013) (S2 Fig.). Western blotting revealed that the vast majority of TbPH1-BioID2-HA was present in the soluble S1 fraction (Fig. 4C), which was used for subsequent analysis. At first glance, this result appears to disagree with previous findings from the 'MT sieving' fractionation, which employs comparable amounts of non-ionic detergent and buffers of low ionic strength; however, we should emphasise that 'MT sieving' fractionation uses a different detergent for a shorter incubation time and at a lower temperature in comparison to the BiolD purification (see Methods), which likely explains this difference.

Next, the S1 fraction was incubated with streptavidin-coated magnetic beads to capture biotinylated proteins, which were subsequently trypsinized on beads prior to liquid chromatography-tandem mass spectroscopy (LC-MS/MS). A mock control using the parental cell line lacking BiolD2 expression was processed in parallel. A total of 1,131 proteins were detected with high confidence in at least one of three biological replicates (Andromeda Protein Score $\geq 20$; $>1$ unique peptide per protein) (S2 dataset). Following imputation of missing values, seven proteins were shown to be preferentially 
215

216

217

218

219

220

221

222

223

224

225

226

227

228

229

230

231

232

233

234

235

236

237

238

239

240

241

242

243

244

245

246

247

248

249

250

251

252

253

254

255

256

257

258

biotinylated by TbPH1-BiolD2-HA, as visualised by plotting the -10 log t-test $p$ value versus the test difference in a volcano plot (Fig. 4D). Statistically significant hits are found above the cut-off curve in this plot.

TbKifX2 was the most enriched protein based on both parameters, consistent with its strong interaction with $\mathrm{TbPH} 1$. As expected, $\mathrm{TbPH} 1$ is also among the enriched proteins, indicating that TbPH1-BiolD2-HA biotinylated itself and/or a nearby untagged, endogenous form. The sub-cellular location of the five novel proteins was determined using the TrypTag protein localization resource (Dean et al., 2017). This allowed us to already exclude one of them (Tb927.10.12110) as a contaminant, given its nuclear localization. A putative kinesin with a C-terminal PH domain (Tb927.6.2880) is enriched in the basal body. Two proteins are enriched in the flagellar pocket: a dynamin-like protein 1/2 (DLP2, Tb927.3.4760; DLP1, Tb927.3.4720) and a flagellar pocket protein FP45 (Tb927.9.9730). DLP1/2 is involved in clathrin-mediated endocytosis (Morgan et al., 2004; Benz et al., 2017) as well as in mitochondrial scission (Chanez et al., 2006; Benz et al., 2017). Interestingly, FP45 has also been demonstrated to be a soluble protein that associates with the membrane surrounding the flagellar pocket by immunogold labelling in an independent study (Gheiratmand et al., 2013). Furthermore, TrypTag localization of FP45 demonstrates a line emanating from the flagellar pocket toward the anterior in many cells, similar to TbPH1. Only a putative flavin-trafficking protein (Tb927.8.1950) does not have a TrypTag localization entry at this time. However, this protein was found among those that interact with TOEFAZ1 (alias CIF1, (Zhou et al., 2018)), a protein that associates with the tip of the extending FAZ (Fig. 4E) (Hilton et al., 2018). Furthermore, Hilton and colleagues $\mathrm{N}$-terminally tagged Tb927.8.1950 to determine its localization by IFA, which exhibited an enriched signal in the vicinity of the kinetoplast. Also, both TbPH1 and TbKifX2 were found within the TOEFAZ1-BiolD proximity proteome with high statistical significance $(P=0.001138$ and 0.0032861 , respectively), along with two other proteins biotinylated by TbPH1-BiolD2-HA (Fig. 4E-F) (Hilton et al., 2018).

We also compared the TbPH1 proximity proteome to those of TbMORN1, a protein that is part of the hook complex (Morriswood et al., 2013), and TbSpef1, a protein localized to the MtQ (Dong et al., 2020) (Fig. 4F). Tellingly, there was no overlap among any of these proteomes. We conclude that none of members of the TbPH1 proximity proteome are part of the hook complex and that TbSpef1 and $\mathrm{TbPH} 1$ are not near each other given that the radius of biotinylation of adjacent proteins by the BiolD biotin ligase is approximately $10 \mathrm{~nm}$ (Kim et al., 2014).

These observations confirm the tight interaction between TbPH1 and TbKifX2. They also suggest that these proteins associate with the basal body, a cytoskeletal element near the flagellar pocket, as well as the FAZ given the localization of the biotinylated proteins. Thus, we proceeded to test the basal body and FAZ localization suggested by the TbPH1-BiolD (Fig. 4) and IFA (Figs. 2B, 3D and E) results.

\section{TbPH1 and TbKifX2 localize to the microtubule quartet within the cytoskeleton}

We next decided to address whether TbPH1 and TbKifX2 localize to or near the FAZ, as was suggested by the $\mathrm{TbPH} 1$ proximity proteome. Cytoskeletons were detergent-extracted from the TbPH1-V5 and TbKifX2-HA expressing cells to visualize any potential localization to discrete cytoskeletal structures. Indeed both proteins co-localized to a long structure running along the longaxis of the cytoskeleton adjacent to the flagellum (Figs. 5A and S3A). Furthermore, detergent extraction solubilized the cell body signal (Figs. 3D and E), confirming it represented the cytosolic population of TbPH1 and TbKifX2 (Figs 2A and $3 \mathrm{C}$ ). The specificity of the antibodies recognizing V5 
259

260

261

262

263

264

265

266

267

268

269

270

271

272

273

274

275

276 and HA on extracted cytoskeletons was verified by a lack of signal in the parental cell line lacking either of these epitopes (Fig. S3B).

We proceeded to identify specifically which cytoskeletal element TbPH1 and TbKifX2 associate with. We used antibody recognizing TbKifX2-HA as a proxy for the TbKifX2-TbPH1 complex because of their demonstrated tight interaction (Fig 3), and their co-localization on detergent-extracted cytoskeletons. We note that in contrast to the TbPH1 co-localization assay depicted in Figs. 5A and $\mathrm{S} 3 \mathrm{~A}$, we used rabbit antibody recognizing the $\mathrm{HA}$ tag to allow us to counterstain with antibodies raised in mouse and rat.

We found TbKifX2-HA exhibited a strong signal further toward the proximal region of the flagellum that tapered in signal intensity in a line juxtaposed with the FAZ filament (Figs. 5B and S3D). This region of strong TbKifX2-HA signal co-localized with the basal bodies (Figs. 5C and S3C). This pattern led us to investigate whether the kinesin was bound to the MtQ, as it originates close to the basal body and is considered a part of the FAZ (Lacomble et al., 2009; Sunter and Gull, 2016). To this end, we used the monoclonal antibody 1B41 recognizing the MtQ (Gallo et al., 1988), a somewhat contentious claim that is belied by its use as a MtQ marker in subsequent studies (Rotureau et al., 2011) (see Experimental Procedures for more details about the $1 B 41$ batch used here). Indeed, TbKifX2-HA shows co-localization with 1B41 (Figs. 5D and S3E), suggesting that TbKifX2 may associate with the MtQ.

To verify that TbKifX2 indeed binds the $M t Q$, we employed expansion microscopy (ExM), which enlarges cells by embedding them within a swellable polyacrylamide matrix prior to immunolabelling to allow examination of cellular structures in greater detail (Gambarotto et al., 2019). ExM has recently been implemented in T. brucei (Gorilak et al., 2021; Amodeo et al., 2021), and accentuates the part of MtQ that wraps around the flagellar pocket upon immunolabeling with antibody recognizing MT-incorporated, acetylated $\alpha$-tubulin (Fig 6A) (Gorilak et al., 2021). Additionally, this procedure allows the proximal MtQ to be distinguished from the nearby hook complex, which lacks MTs (Esson et al., 2012).

Performing ExM allowed us to localize TbPH1-V5 or TbKifX2-HA to the part of the MtQ that spirals around the flagellar pocket, as demonstrated by the co-localization of each epitope tag with acetylated $\alpha$-tubulin in both 3D reconstruction of expanded cells and individual confocal focal planes (Figs. 6A-F). The associated V5 or HA signal was not discernible beyond the point of the MtQ joining the corset MTs, where the signal of FAZ constituents, such as CIpGM6 (Hayes et al., 2014), starts (c.f. Figs. 6A and C with Fig. S4). The fact, that the signal of TbPH1-V5 or TbKifX2-HA was apparent only in the part of the MtQ around the flagellar pocket is consistent with this being the region of the highest concentration of both proteins in the cell based on IFA (Figs. 3D-E), as well as with a lower sensitivity of ExM due to dilution of epitopes stemming from specimen expansion. Taken altogether, ExM reveals that $\mathrm{TbPH} 1$ and TbKifX2 localize to the MtQ element of the T. brucei cytoskeleton. Additionally, we observed a punctate signal of an anti-V5 or anti-HA antibody in the expanded cell body (Figs. 6C-F), consistent with the significant cytosolic fraction of both proteins (Figs. 2A, 3C-E).

\section{Depletion of TbPH1 and TbKifX2 causes prominent morphological defects to the posterior end of $T$. brucei}

To assay the function of the novel kinesin TbKifX2 and its associated kinesin-like protein TbPH1, we depleted their expression by doxycycline-induced RNAi in the cell line expressing TbPH1-V5 and TbKifX2-HA. The downregulation of either protein alone only marginally affected the growth of $T$. brucei in comparison to the non-induced cells, despite efficient depletion of each of the respective 
303 tagged proteins (Fig. 7A, Fig. S5A). After 6 days of RNAi-silencing of TbKifX2, we fractionated the 304 cytoskeleton from the cytosol under low salt conditions (Fig. 7B). Consistent with 'MT sieving' 305 fractionation (Figs. 2A and 3C) and IFA (Figs 3D-E and 5A), western blot detection revealed TbKifX2-

$306 \mathrm{HA}$ and TbPH1-V5 in both cytoskeletal and cytosolic fractions in cells grown in the absence of 307 tetracycline, in which neither protein was downregulated (Fig. 7B). However, TbPH1 was 308 preferentially depleted from the cytoskeleton fraction upon TbKifX2 silencing. This result indicates 309 that TbKifX2 recruits TbPH1-V5 to the MtQ (Fig. 7B).

310 To get a more robust RNAi phenotype for phenotypic analysis, we generated cell lines in which both 311 proteins were downregulated, which showed more pronounced growth inhibition than the single 312 knock-downs (Fig. 7A). Growth slowed after 3 days of RNAi induction and did not reach levels of the 313 uninduced counterparts at any point during the 7 day time course (Fig. S5B). Depletion of both 314 proteins was confirmed by western blotting (Fig. S5B, inset), although neither protein was decreased below the detection limits of this assay, perhaps explaining the lack of a more severe growth phenotype.

Because both TbPH1 and TbKifX2 are modified in a way suggestive of post-translational regulation (Fig. 1), plus both associate with proteins that may regulate the cell cycle (e.g. FP45) (Gheiratmand et al., 2013), we wondered whether the growth inhibition of the double RNAi knockdown is due to a cell cycle defect. Thus, we assayed the proportion of cell cycle stages present over a course of 7 days of TbPH1/TbKifX2 depletion, sorting individual DAPI-stained cells into different cell cycle stages by scoring their number of nuclei $(\mathrm{N})$ and kinetoplasts (K) (Robinson et al., 1995). The proportion of $1 \mathrm{~N} 1 \mathrm{~K}$ cells decreased while $2 \mathrm{~N} 2 \mathrm{~K}$ cells doubled at the same time from around $10 \%$ of the population to about $20 \%$ (Fig. S5C). The number of zoids (cells with 1 kinetoplast and lacking a nucleus) reached a peak at day 5 , making up about $7 \%$ of the population, which may suggest problems with cytokinesis. However, we did not observe the consequent emergence of $2 \mathrm{~N} 1 \mathrm{~K}$ or multinucleated cells, arguing against a specific cytokinesis defect (Robinson et al., 1995). Thus, we conclude that either TbKifX2 and TbPH1 do not play a direct role in cell cycle progression and cytokinesis, or the partial depletion of these proteins did not reach the threshold needed to affect cytokinesis. Thus we looked for other phenotypes that would explain the moderately decreased fitness of these cells.

We assayed the MtQ and FAZ by IFA after 5 days of RNAi depletion and observed no defects in either of these structures, indicating that TbPH1 and TbKifX2 do not play a role in their biogenesis (Fig. S5D). However, by phase contrast microscopy we noticed the emergence of two morphological phenotypes, namely multiple cells joined together on their posterior end, a phenotype resembling abscission defects (Ralston et al., 2006; Benz et al., 2012) and single cells with protrusions from the posterior end (Fig. 7C).

To better visualize these phenotypes, we observed these cells by scanning electron microscopy (Fig. 7D). While control cells showed normal trypomastigote morphology (Fig. 7D), we regularly observed cells with multiple protrusions (arrows) originating from the posterior end in the induced population (Fig. 7D). The occurrence of these cell types was also corroboratively found in transmission electron microscopy, which in addition provided evidence that these protrusions appear to contain normal cellular contents and were surrounded by subpellicular MTs (Fig. S6A-B).

This effect of TbPH1/TbKifX2-depletion resembled the RNAi-phenotype of two tubulin-tyrosineligase-like (TTLL) proteins, which post-translationally modify the C-terminal tails of $\alpha$ - and $\beta$-tubulin by addition of polyglutamate side chains (Jentzsch et al., 2020). Upon depletion of either TTLL, protrusions were observed emanating from the posterior end, which prompted the authors to name this morphological change the 'glove' phenotype. To determine whether TbPH1/TbKifX2 
downregulation truly phenocopies that of each TTLL, we immunolabelled cells 5 days post RNAiinduction with antibodies recognizing glutamyl side chains (GT335 antibody) and tyrosinated $\alpha$ tubulin (YL 1/2 antibody) (Fig. 5C and S3C); the latter antibody was used previously to visualize the basal bodies, where it additionally cross-reacts with TbRP2 (Andre et al., 2014). Upon depletion of either TTLL, polyglutamylation was decreased and $\alpha$-tubulin tyrosination increased in the posterior end, from which the protrusions emerged (Jentzsch et al., 2020). We did not observe either of these changes in post-translational modifications upon TbPH1/TbKifX2 silencing by observing them on individual cells by IFA (Fig. S6C) or the whole cell population by western blot analysis (Fig. S6D), suggesting the mechanism underlying the emergence of posterior-end protrusions differs from that of the TTLLs.

\section{DISCUSSION}

Kinesins and related kinesin-like proteins constitute one of the largest protein families encoded by the $T$. brucei genome (Berriman et al., 2005) and are represented by diverse gene repertoires in other trypanosomatids as well (El-Sayed et al., 2005; Ivens et al., 2005; Wickstead and Gull, 2006; Wickstead et al., 2010b). Among the eukaryotes, trypanosomatids have experienced one of the largest expansions of the kinesin motor superfamily, suggesting these proteins endow trypanosomes with unique biological properties, many of which still await elucidation (Berriman et al., 2005; Wickstead and Gull, 2006; Wickstead et al., 2010b). Indeed, this expansion has resulted in the emergence of two trypanosomatid-specific clades of kinesins, named X-1 and X-2. A kinesin belonging to the former, named FCP2/TbKinX1, has been shown to maintain a connection of a new flagellum's distal tip along the side of the old flagellum, thus facilitating the unique mechanism of templated flagellar replication in T. brucei (Varga et al., 2017).

In this work, we have shed light on the function of a member of the trypanosomatid-specific X-2 clade, which we named TbKifX2. We show that TbKifX2 is localized to the MtQ component of the cytoskeleton while also maintaining a cytosolic fraction. Thus, TbKifX2 is the first motor protein that has been demonstrated to localize to the $\mathrm{MtQ}$, a cytoskeletal component that is considered to be part of the FAZ and restricted to trypanosomatids (Sunter and Gull, 2016).

TbKifX2 recruits TbPH1, a likely catalytically-dead, kinesin-like protein with a C-terminal PH domain, to the MtQ. Given that TbPH1 remains in the cytosolic fraction upon TbKifX2 depletion argues that both proteins do not always interact. This notion is also consistent with the enrichment of TbPH1 on the anterior tip of the cell, which was not observed in KifX2. However, when TbKifX2 and TbPH1 do interact on the MtQ, the part of the cytoskeleton where both proteins co-localize, they interact with a strong affinity that persists in high salt concentrations, a condition that usually disrupts noncovalent interactions between the CC domains (Grigoryan and Keating, 2008).

As far as we know, there are not many reports of kinesin interactions with a protein with a kinesin-

like structure, but still being catalytically inactive. The most extensively characterized example being the budding yeast Kar3 kinesin and Vik1, which confers to the Kar3/Vik1 complex a strong interaction with a microtubule (Allingham et al., 2007). We hypothesize that the TbKifX2/TbPH1 complex may represent an adaptation for binding the MtQ. How the TbKifX2/TbPH1 complex preferentially interacts with the MtQ over the corset microtubules is an intriguing question. It has been suggested that the MtQ contains $\beta$-tubulin with a unique but still unknown modification that is recognized by the 1B41 monoclonal antibody (Gallo et al., 1988; Gallo and Precigout, 1988), and could have an increased affinity to the kinesin complex investigated here. Alternatively, the kinesins 
could be activated at a specific site, for example at the proximal end of the MtQ, similar to the yeast kinesin Kip2 being recruited to the minus ends of microtubules by the activity of the spindle pole bodies (Chen et al., 2019). However, at this juncture, we do not know whether TbKifX2 and TbPH1 interaction occurs prior to or after the proteins bind the MtQ.

The TbPH1 proximity proteome obtained via BiolD labelling reassuringly revealed a protein cohort that is enriched around the proximal end of the MtQ. Among these were another kinesin with a PH domain that was localized to the basal bodies. Also, two proteins were found to be associated with the flagellar pocket, including FP45 (Gheiratmand et al. , 2013). The other protein is interestingly a putative flavin-trafficking protein, containing an ApbE-like domain, which is common in prokaryotes but a rare occurrence in eukaryotic proteins (Schenk et al., 2021). What an enzyme potentially influencing redox is doing in association with the MtQ is another open question that has been uncovered in this study.

The TbPH1 proximity proteome was also informative in terms of proteins that were missing. One group of absent proteins are those identified to be part of the hook complex (Morriswood et al., 2013), allowing us to conclude that TbPH1 does not associate with this cytoskeletal structure which lacks MTs (Esson et al., 2012). Also, the eleven high confidence proteins found to be in the TbSpef1 proximity proteome were not found in our study (Dong et al. , 2020). This is quite surprising given that TbSpef1 also localized to the proximal MtQ (Gheiratmand et al., 2013). This may indicate that these two proteins maintain a constant spatial separation, even if they both seemingly localize to the same, constrained part of the cell. Indeed the biotin ligase fused to TbPH1 to mediate BiolD biotinylates proteins within a $10 \mathrm{~nm}$ radius (Kim et al., 2014), suggesting that TbSpef1 and TbPH1, and perhaps other MtQ-binding proteins, may be partitioned at nanoscales. Consistent with this notion, only one of the eleven proteins in the TbSpef1 proximity proteome was found in that of TOEFAZ, namely the known FAZ protein named FAZ 10 (Moreira et al., 2017). The higher degree of overlap between the proximity proteomes of TOEFAZ, which is enriched at the distal tip of the FAZ (Hilton et al., 2018; Zhou et al., 2018), and TbPH1 in comparison to the TbSpef1 proximity proteome indicates that perhaps TbPH1 is more distal to TbSpef1 in the MtQ.

Simultaneous depletion of TbPH1 and TbKifX2 does not affect the overall morphology of MtQ or FAZ, indicating they are likely not involved in the biogenesis of these cellular structures. As these single copy organelles must be faithfully replicated during cell proliferation, it is consistent with the double knockdown having a minimal impact on the cell cycle. Nevertheless, TbKifX2/ TbPH1 downregulation has a striking morphogenesis phenotype, namely the accumulation of protrusions from the posterior end of $T$. brucei. The intracellular contents of these protrusions appear to be comparable to the rest of the cell and they are also surrounded by subpellicular MTs. Interestingly, these protrusions are reminiscent of the 'glove phenotype' observed upon depletion of two TTLL enzymes, which are responsible for post-translational modifications appending the $C$-terminal tails of $\alpha$ - and $\beta$-tubulin (Jentzsch et al., 2020).

However, we can now only speculate about the nature of these posterior extrusions. For one, simultaneous TbPH1 and TbKifX2 depletion did not affect polyglutamylation or tyrosination of tubulins, indicating that these proteins do not play a role in regulating either of these posttranslational modifications as is the case for either TLL (Jentzsch et al., 2020). Malfunction of regulated polyglutamylation and tyrosination led to mislocalization of EB1, a MT-plus-end-binding protein that binds to the MT corset at the posterior tip (Sheriff et al., 2014; Jentzsch et al., 2020). It was proposed that EB1 proteins may dock onto tubulins with the aforementioned post-translational modifications (Jentzsch et al., 2020). So, the malformations seen in TbPH1/TbKifX2 may affect EB1 or other such MT-plus-end-binding proteins, leading to uncontrolled MT growth or aberrant MT 
438

439

440

441

442

443

444

445

446

447

organization. However, it should be noted that EB1 was not identified in the TbPH1 proximity proteome, so any effect on this protein may be an indirect consequence of RNAi-silencing. The protrusions may also be a consequence of delayed or uncoordinated cytokinesis or represent mechanical damage to the posterior ends due to faulty separation of daughter cells at the final stage of cytokinesis. However, arguing against protrusions arising from a putative cytokinesis defect is that they were not observed in T. brucei unable to pull apart due to motility defects (Ralston et al., 2006).

The finding that the depletion of proteins that associate with the MtQ can affect the gross morphology of $T$. brucei was unexpected. Unfortunately, the proteins that were identified in the $\mathrm{TbPH} 1$ proximity proteome do not provide an obvious explanation that would link the phenotype to the localization of TbKifX2 and TbPH1. Nevertheless, we have uncovered an intriguing relationship between the MtQ and T. brucei morphogenesis that is worthy of further exploration.

\section{EXPERIMENTAL PROCEDURES}

\section{Cells}

Procyclic SmOxP9 cells (Poon et al., 2012) were grown in SDM79 with $1 \mu \mathrm{g} / \mathrm{ml}$ of puromycin. Cell lines bearing epitope tags were grown with $50 \mu \mathrm{g} / \mathrm{ml}$ hygromycin (TbPH1-V5), $15 \mu \mathrm{g} / \mathrm{ml} \mathrm{G418}$ (TbKifX2-HA) and $10 \mu \mathrm{g} / \mathrm{ml}$ blasticidin (TbPH1-BiolD2-HA). Selection for the RNAi constructs was with $2.5 \mu \mathrm{g} / \mathrm{ml}$ phleomycin (TbKifX2 RNAi, TbPH1 RNAi and TbKifX2+TbPH1 RNAi).

\section{Plasmids and generation of cell lines}

For epitope tagging at the endogen ous locus with HA and V5, long PCR products were generated with primers TbPH1V5 FW (TTTCTTCCGGTCTTGACTTATTCCGCTCAGGGAAGCTTTATGATTTCTTATGCGA AAAGAGAGTCATACCGCTCCCGTACggttctggtagtggttcc) and TbPH1V5 RV (ATAATAAAGAGGAAGGGAAG GTAAAGTTCAGAAACAAATTCTGTTGGCTCCTGATAACACTCTCATATTTCCTTCACCGCccaatttgagagacctgtg c) and primer TbKifX2HA FW (AACTACAGTTGCAAATGTGCATGATAGGAAGAAGTTGCCTCACGATGGAGC GTTGGAAAGCGGAACATGTCGGAACCGCAggttctggtagtggttcC) and TbKifX2HA RV (CATTTTAAACAATTTC TCCT TCCCTCTTTTTTCACTCATTCATTCATTCATTCATTCACCACCTTCTTTTTTTTTGCCTCctgtgC) using pPOT-V5-HygR and pPOT-HA-NeoR vectors as templates (based on (Kaurov et al., 2018) and modified from pPOTv4 (Dean et al., 2017)). For tagging with the BiolD2 ligase (38), a modified version of pPOTv7-Blast-mNG (Pyrih et al., 2020) was used with the aforementioned primers for $\mathrm{TbPH} 1$ endogenous locus tagging. $50 \mu \mathrm{PCR}$ reactions were directly transfected into procyclic SmOxP9 cells using the Amaxa Nucleofactor electroporator and selection occurred approximately 16 hours after electroporation.

To create a vector to simultaneously downregulate both TbPH1 and TbKifX2, a fragment of each (as suggested by RNAit2 software (https://dag.compbio.dundee.ac.uk/RNAit/) (Redmond et al., 2003)) was PCR amplified using primers TbPH1-RNAi-Fw (TAATtctagaGTTGCGTGATGAGCTTCAAA), TbPH1RNAi-Rv (TATAaagcttCTCCTCTAGCACCGTTTTGC), TbKifX2-RNAi-Fw (TAATggatccCACCGCCATTCTGCA AACAA) and TbKifX2-RNAi-Rv (TATAtctagaGTCATTTGCGTGGGCGATAC) and cloned into BamHI-HindIII sites of p2T7-177 (Wickstead et al., 2002) in a three way ligation using Xbal as the restriction site in between the two RNAi fragments. The plasmid was linearised with Notl before electroporation.

\section{RNAi and growth curves}

Procyclic form cell lines for depletion of either TbPH1 or TbKifX2 were induced at a density of $2 \times 10^{6}$ cells $/ \mathrm{ml}$ with $1 \mu \mathrm{g} / \mathrm{ml}$ doxycycline and growth monitored daily with a Z2 Coulter Counter Analyzer (Beckman Coulter). Cells were diluted back to the initial cell density every day. Cell lines carrying the 
481 vector for simultaneous depletion of TbPH1 and TbKifX2 were induced at a density of $5 \times 10^{5}$ cells $/ \mathrm{ml}$

482 with $1 \mu \mathrm{g} / \mathrm{ml}$ doxycycline and growth monitored daily with a Neubauer counting chamber. Cells were

483 diluted back to the initial cell density every two days.

\section{DAPI counts}

485 For cell cycle analysis, cells either induced or not for depletion of TbKifX2 and TbPH1 were spread on 486 glass slides, the cell suspension allowed to air-dry and the slides then fixed in methanol at $-20^{\circ} \mathrm{C}$.

487 Slides were rehydrated for 5 minutes in PBS before a drop of ProLong ${ }^{\text {TM }}$ Gold antifade reagent with

488 DAPI (ThermoScientific) was added, a coverslip applied and the slide sealed. At least 200 cells were

489 scored according to the number of nuclei and kinetoplasts per slide.

490 Cell fractionation via 'microtubule sieving'

491 To entrap non-soluble and cytoskeletal proteins within the MT corset, a MT sieving technique as

492 described in (Fritz et al., 2015) was employed. The experiment was conducted exactly as described

493 before in (Fritz et al., 2015) (see also S1 Fig.).

\section{V5 immunoprecipitation}

495 For immunoprecipitation (IP) of TbPH1-V5 from procyclic trypanosome lysates, the V5 antibody 496 (Thermo Fisher) was coupled and cross-linked to protein $\mathrm{G}$ coated dynabeads (Thermo Scientific) 497 using $6 \mathrm{mg} / \mathrm{ml}$ dimethyl pimelidate dihydrochloride in $0.2 \mathrm{M}$ triethanolamine. Beads were then 498 washed in IP wash buffer ( $20 \mathrm{mM}$ Tris- $\mathrm{HCl}, \mathrm{pH} 7.7,100 \mathrm{mM} \mathrm{KCl}, 3 \mathrm{mM} \mathrm{MgCl}, 0.5 \%$ TritonX-100, 499 cOmplete $^{\text {TM }}$ EDTA-free protease inhibitor (Roche)) and stored at $4{ }^{\circ} \mathrm{C}$ before further usage. For 500 proteomic analysis of TbPH1 interactions, $1 \times 10^{9}$ PCF cells were pre-fractionated using the MT sieving 501 technique described above. The SN3 lysate was incubated with V5-coupled dynabeads for 24 hours 502 at $4{ }^{\circ} \mathrm{C}$. Following several washes in IP wash buffer, proteins were eluted using low pH glycine buffer. 503 Aliquots were taken of the different steps for western blot analysis.

\section{Western blots}

505 Cell lysates were prepared by boiling in $1 \times$ SDS sample buffer and the equivalent of $2 \times 10^{6}$ cells (RNAi 506 lines) or $1 \times 10^{7}$ cells (IP samples) was loaded per well. Following western blotting, PVDF membranes 507 were blocked for 1 hour in 5\% milk-PBS. Incubation with primary antibodies (anti-V5 at 1:1,000;

508 ThermoScientific, anti-HA at 1:1,000; ThermoScientific, anti-tubulin at 1:5,000; Sigma) was

509 performed at $4{ }^{\circ} \mathrm{C}$ overnight. Secondary antibodies (HRP-coupled anti-mouse or -rabbit lgG; Sigma)

510 were used at a concentration of 1:2,000 and signals were visualised using Clarity Western ECL

511 substrate (Bio-Rad) on a ChemiDoc MP (Bio-Rad).

\section{SYPRO Ruby staining}

513 Following electrophoresis, polyacrylamide gels were placed into fixing solution (7\% glacial acetic 514 acid, 50\% methanol) for 30 minutes at room temperature. Following another, identical fixation step, 515 the gel was incubated with SYPRO Ruby solution overnight at room temperature. A washing step in 516 washing solution ( $7 \%$ glacial acetic acid, 10\% methanol) for 30 minutes at room temperature was 517 followed by three 5 minute washes in milliQ water before imaging on a ChemiDoc MP (Bio-Rad).

\section{Immunofluorescence and cytoskeleton extraction}

519 Approximately $2 \times 10^{6}$ cells were used per slide. Cells were washed in PBS and fixed in $2.3 \%$ PFA in PBS 520 for approximately 30 minutes before being transferred to microscopy slides (ThermoScientific).

521 Following neutralisation in $0.1 \mathrm{M}$ glycine in PBS, slides were incubated in methanol at $-20^{\circ} \mathrm{C}$ 
overnight for permeabilisation. Slides were then rehydrated in PBS and blocked in 1\% BSA in PBS for 1 hour followed by incubation with primary antibody for 1 hour in a humid chamber. The slides were then washed three times with PBS before incubation in AlexaFluor-conjugated secondary antibody (goat anti-rabbit/mouse, used at 1:1,000; Invitrogen). Following three further washes in PBS, a drop of ProLong Gold Antifade reagent with DAPI (ThermoScientific) was added, a coverslip applied and the slide sealed with nail polish. Slides were imaged with a Zeiss Axioscope or an Olympus FluoView Fv1000 confocal microscope.

For immunofluorescence analysis of cells extracted using the 'MT sieving' fractionation method described above the pellet fraction P2 was fixed in 2.3\% PFA as described. All subsequent steps were the same as for whole cell immunofluorescence.

To extract cytoskeletons conventionally, approximately $1 \times 10^{7}$ PCF cells were collected and centrifuged at room temperature for $5 \mathrm{~min}$ at $800 \mathrm{x} \mathrm{g}$ and the supernatant discarded. Thereafter, the cell pellet was washed once in PBS and after resuspension in PBS applied in a drop-wise fashion to Superfrost plus ${ }^{\circledR}$ slides (ThermoScientific). The cells were left to settle before the addition of PEME buffer (100 mM Pipes, pH 6.9, $1 \mathrm{mM} \mathrm{MgSO}_{4}, 2$ mM EGTA, $0.1 \mathrm{mM}$ EDTA) containing 0.5\% (v/v) NP-40 (Igepal) for 10 seconds. This cytoskeleton extraction was followed by a 10 minute fixation step in $4 \%$ PFA. All subsequent steps were as described above for whole cell immunofluorescence.

Antibodies used in immunofluorescence

\begin{tabular}{|l|l|l|}
\hline Antibody & Dilution & Origin \\
\hline anti-HA (produced in rabbit) & $1: 1,000$ & Sigma, Catalog \#: H6908 \\
\hline anti-V5 (produced in mouse) & $1: 1,000$ & $\begin{array}{l}\text { ThermoScientific, Catalog \#: } \\
377500\end{array}$ \\
\hline 1B41 (MtQ) ${ }^{1}$ & $1: 1,000$ & (Gallo et al., 1988) \\
\hline L3B2 & $1: 10$ & (Kohl et al., 1999) \\
\hline YL1/2 & $1: 50$ & (Sherwin and Gull, 1989) \\
\hline GT335 & $1: 2000$ & $\begin{array}{l}\text { Adipogen Life Sciences, } \\
\text { Catalog \#: AG-20B-0020 }\end{array}$ \\
\hline${ }^{1}$ IgM purified from hybridoma supernatant and not mouse ascitic fluid as in original report.
\end{tabular}

\section{Scanning and transmission electron microscopy}

For TEM, cell pellets were high-pressure frozen, freeze substituted in the presence of $2 \%$ OsO4 in acetone, and embedded into Spi-Pon812 resin (SPI) as described previously (Kaurov et al., 2018). For SEM of the TbPH1/TbKifX2 RNAi cell line, cells were fixed in $2.5 \%$ glutaraldehyde in $100 \mathrm{mM}$ PBS overnight at $4^{\circ} \mathrm{C}$ and then spotted onto poly-l-lysine-coated glass cover slips. The cells were postfixed in $2 \%$ osmium tetroxide in $100 \mathrm{mM}$ PBS for $1 \mathrm{~h}$ at room temperature and finally washed in the same buffer. After dehydration cells were critical-point dried, coated with gold palladium and imaged.

\section{Expansion microscopy}

Expansion microscopy samples were prepared as described previously (Gorilak et al., 2021). In brief, $1 \times 10^{6}$ cells were fixed overnight in a solution containing $4 \%$ formaldehyde and $4 \%$ acrylamide in PBS and adhered to a poly-L-lysine (Sigma, P4707) coated coverslip. The cells were gelated for $30 \mathrm{~min}$ at $37^{\circ} \mathrm{C}$ in PBS supplemented with $19 \%$ sodium acrylate, $10 \%$ acrylamide, and $0.1 \% \mathrm{~N}, \mathrm{~N}^{\prime}-$ Methylenebisacrylamide, $0.5 \% \mathrm{~N}, \mathrm{~N}, \mathrm{~N}^{\prime}, \mathrm{N}^{\prime}$-tetramethylethylenediamine, and $0.5 \%$ ammonium persulfate. The specimens were further denatured by a 2 hour incubation at $95^{\circ} \mathrm{C}$ in a buffer 
556 consisting of $50 \mathrm{mM}$ tris(hydroxymethyl)aminomethane-hydrochloride, $200 \mathrm{mM}$ sodium chloride, $557200 \mathrm{mM}$ sodium dodecyl sulphate, $\mathrm{pH}$ 9.0, and expanded by three $20 \mathrm{~min}$ incubations with $15 \mathrm{ml}$ of 558 ultrapure water.

559 Thereafter, the gels were incubated overnight first with a mixture of anti-HA (Cell Signaling 560 Technology, 3724S; used at 1:250) and C3B9 ((Woods et al., 1989), used at 1:10), anti-V5 (Sigma, 561 V8137-.2MG; used at 1:250) and C3B9 or anti-ClpGM6 ((Hayes et al., 2014), used at 1:200) and C3B9 562 antibodies, followed by washes and an overnight incubation with a mixture of secondary antibodies 563 (Invitrogen, A11001 and A21428; used at 1:500). Both primary and secondary antibodies were 564 diluted in PBS supplemented with $2 \%$ bovine serum albumin. Finally, the gels were washed with 565 ultrapure water.

566 Prior to imaging pieces of gels containing stained expanded cells was transferred to a glass-bottom 567 dish coated with poly-L-lysine, and imaged using a Leica TCS SP8 confocal microscope with an HC PL 568 apochromatic 63x/NA 1.40 oil immersion objective. Z-stacks were acquired with the step size of 100 $569 \mathrm{~nm}$. Confocal z-stacks were processed in Fiji (Schindelin et al., 2012). 3D reconstructions were 570 performed in the 3D viewer plugin.

\section{BiolD}

PCF cells (TbPH1-BiolD2-HA and SmOxP9 as controls) were grown in the presence of $50 \mu \mathrm{M}$ biotin for 24 hours. For proximity-dependent biotin identification (BiolD), $10^{9}$ PCF cells were extracted in PEME buffer (100 mM Pipes, pH 6.9, $1 \mathrm{mM} \mathrm{MgSO}_{4}, 2$ mM EGTA, $0.1 \mathrm{mM}$ EDTA) containing $0.5 \%$ (v/v) NP-40 (Igepal) for 15 minutes at room temperature resulting in extract E1. Following centrifugation at $3,400 \times \mathrm{g}$ for 2 minutes, supernatant $\mathrm{S} 1$ was created and pellet $\mathrm{P} 1$ was further processed by extraction in lysis buffer (0.4\% SDS, $500 \mathrm{mM} \mathrm{NaCl}, 5 \mathrm{mM}$ EDTA, $1 \mathrm{mM}$ DTT, $50 \mathrm{mM}$ Tris-HCl, pH7.4). Another centrifugation step at $16,000 \times \mathrm{g}$ for 10 minutes created supernatant $\mathrm{S2}$. Both supernatants, S1 and S2, were then incubated with streptavidin-conjugated Dynabeads (company) for 4 hours at 4 ${ }^{\circ} \mathrm{C}$. An aliquot of flow through samples F1 and F2 were retained for western blotting and the dynabeads were washed five times with PBS. A small sample of the beads was then resuspended in 2x SDS PAGE buffer and boiled, while the remainder of the beads was stored at $-80^{\circ} \mathrm{C}$ until further processing for mass spectrometry analysis.

\section{Mass spectroscopy analysis of captured biotinylated proteins}

Trypsin-digestion of captured biotinylated proteins was performed on bead prior to liquid chromatography-tandem mass spectroscopy (LC-MS/MS) as previously described (Pyrih et al., 2020). Data was processed using MaxQuant (Cox and Mann, 2008) version 1.6.14 which incorporates the Andromeda search engine (Cox et al., 2011). Proteins were identified by searching a protein sequence database containing T. brucei brucei 927 annotated proteins (Version 51, TriTrypDB (Aslett et al., 2009), http://www.tritrypdb.org/) supplemented with frequently observed contaminants. Search parameters specified an MS tolerance of $6 \mathrm{ppm}$, an MS/MS tolerance at $0.5 \mathrm{Da}$ and full trypsin specificity, allowing for up to two missed cleavages. Carbamidomethylation of cysteine was set as a fixed modification and oxidation of methionine and $\mathrm{N}$-terminal protein acetylation were allowed as variable modifications. The experimental design included matching between runs for biological replicates. Peptides were required to be at least 7 amino acids in length, with false discovery rates (FDRs) of 0.01 calculated at the levels of peptides, proteins and modification sites based on the number of hits against the reversed sequence database. The obtained data was subsequently processed in Perseus version 1.6 .14 as described in (Zoltner et al., 2020). 
600 The mass spectrometry proteomics data have been deposited to the ProteomeXchange Consortium

601 via the PRIDE partner repository with the dataset identifier PXD025802.

602

\section{ACKNOWLEDGEMENTS}

604 We thank Keith Gull (University of Oxford), Linda Kohl (Muséum National d'Histoire Naturelle), Bill

605 Wickstead (University of Nottingham), and Ziyin Li (University of Texas Medical School at Houston)

606 for helpful comments, Susanne Kramer (University of Würzburg), Cynthia He (National University of

607 Singapore), and Chris de Graffenried (Brown University) for antibodies, Peter Gorilak (Institute of

608 Molecular Genetics) for assistance with imaging, as well as Karel Harant and Pavel Talacko (BIOCEV,

609 Prague) and Zbyněk Zdráhal and David Potěšil (CEITEC, Brno) for mass spectroscopy analysis on BioID

610 samples and excised bands, respectively. This work was supported by the Czech Science Foundation

611 grants 20-23513S to HH, and 21-09283S and ERC CZ LL1601 to JL, the ERD funds of the Czech

612 Ministry of Education 16_019/0000759 to HH and JL, and Biolmaging grant LM2018129 to MV. Work

613 in the VV laboratory was supported by an EMBO Installation Grant and by the J. E. Purkyne

614 Fellowship of the Czech Academy of Sciences.

\section{Author contributions}

617 Conceptualization (CB, NM, SK, VV, HH), formal analysis (CB, NM, SK, HV, MV, VV, HH), investigation

618 (CB, NM, SK, HV, MV), visualization (CB, VV, HH), writing - original draft (CB, HV, JL, VV, HH), funding 619 acquisition (JL, VV, HH), project administration (HH).

\section{REFERENCES}

622 Albisetti, A., Florimond, C., Landrein, N., Vidilaseris, K., Eggenspieler, M., Lesigang, J., et al. (2017)

623 Interaction between the flagellar pocket collar and the hook complex via a novel microtubule-

624 binding protein in Trypanosoma brucei. PLoS Pathog 13: e1006710

625 https://pubmed.ncbi.nlm.nih.gov/29091964/.

626 Allingham, J.S., Sproul, L.R., Rayment, I., and Gilbert, S.P. (2007) Vik1 Modulates Microtubule-Kar3

627 Interactions through a Motor Domain that Lacks an Active Site. Cell 128: 1161-1172

628 https://pubmed.ncbi.nlm.nih.gov/17382884/.

629 Amodeo, S., Kalichava, A., Fradera-Sola, A., Bertiaux-Lequoy, E., Guichard, P., Butter, F., and

630 Ochsenreiter, T. (2021) Characterization of the novel mitochondrial genome segregation factor

631 TAP110 in Trypanosoma brucei. J Cell Sci 134: jcs.254300

632 http://jcs.biologists.org/lookup/doi/10.1242/jcs.254300.

633 An, T., and Li, Z. (2018) An orphan kinesin controls trypanosome morphology transitions by targeting 634 FLAM3 to the flagellum. PLOS Pathog 14: e1007101

635 https://dx.plos.org/10.1371/journal.ppat.1007101.

636 Andre, J., Kerry, L., Qi, X., Hawkins, E., Drižyte, K., Ginger, M.L., and McKean, P.G. (2014) An

637 alternative model for the role of RP2 protein in flagellum assembly in the African trypanosome. J Biol

638 Chem 289: 464-475.

639 Aslett, M., Aurrecoechea, C., Berriman, M., Brestelli, J., Brunk, B.P., Carrington, M., et al. (2009)

640 TriTrypDB: A functional genomic resource for the Trypanosomatidae. Nucleic Acids Res 38: D457- 
641 D462 http://tritrypdb.org.

642 Benz, C., Clucas, C., Mottram, J.C., and Hammarton, T.C. (2012) Cytokinesis in bloodstream stage

643 Trypanosoma brucei requires a family of katanins and spastin. PLoS One 7: e30367.

644 Benz, C., Stř́ibrná, E., Hashimi, H., and Lukeš, J. (2017) Dynamin-like proteins in Trypanosoma brucei:

645 A division of labour between two paralogs? PLoS One 12: e0177200

646 https://pubmed.ncbi.nlm.nih.gov/28481934/.

647 Berriman, M., Ghedin, E., Hertz-Fowler, C., Blandin, G., Renauld, H., Bartholomeu, D.C., et al. (2005)

648 The genome of the African trypanosome Trypanosoma brucei. Science 309: 416-422

649 http://dx.doi.org/10.1126/science.1112642.

650 Bertiaux, E., Mallet, A., Rotureau, B., and Bastin, P. (2020) Intraflagellar transport during assembly of 651 flagella of different length in Trypanosoma brucei isolated from tsetse flies. J Cell Sci 133

652 https://pubmed.ncbi.nlm.nih.gov/32843573/.

653 Burkhard, P., Stetefeld, J., and Strelkov, S. V. (2001) Coiled coils: A highly versatile protein folding 654 motif. Trends Cell Biol 11: 82-88 https://pubmed.ncbi.nlm.nih.gov/11166216/.

655 Chanez, A.-L., Hehl, A.B., Engstler, M., and Schneider, A. (2006) Ablation of the single dynamin of $T$.

656 brucei blocks mitochondrial fission and endocytosis and leads to a precise cytokinesis arrest. J Cell Sci

657 119: 2968-74 http://www.ncbi.nlm.nih.gov/pubmed/16787942.

658 Chen, X., Widmer, L.A., Stangier, M.M., Steinmetz, M.O., Stelling, J., and Barral, Y. (2019) Remote 659 control of microtubule plus-end dynamics and function from the minus-end. Elife 8: 1-32.

660 Cox, J., and Mann, M. (2008) MaxQuant enables high peptide identification rates, individualized 661 p.p.b.-range mass accuracies and proteome-wide protein quantification. Nat Biotechno/ 26: 13676621372 https://www.nature.com/articles/nbt.1511.

663 Cox, J., Neuhauser, N., Michalski, A., Scheltema, R.A., Olsen, J. V., and Mann, M. (2011) Andromeda:

664 A peptide search engine integrated into the MaxQuant environment. J Proteome Res 10: 1794-1805

665 https://pubmed.ncbi.nlm.nih.gov/21254760/.

666 Dean, S., Sunter, J.D., and Wheeler, R.J. (2017) TrypTag.org: A Trypanosome Genome-wide Protein

667 Localisation Resource. Trends Parasito/ 33: 80-82 https://pubmed.ncbi.nlm.nih.gov/27863903/.

668 Dong, X., Lim, T.K., Lin, Q., and He, C.Y. (2020) Basal Body Protein TbSAF1 Is Required for 669 Microtubule Quartet Anchorage to the Basal Bodies in Trypanosoma brucei. mBio 11: e00668-20 670 http://mbio.asm.org/content/11/3/e00668-20.abstract.

671 El-Sayed, N.M., Myler, P.J., Bartholomeu, D.C., Nilsson, D., Aggarwal, G., Tran, A.N., et al. (2005) The 672 genome sequence of Trypanosoma cruzi, etiologic agent of Chagas disease. Science 309: 409-415 673 https://pubmed.ncbi.nlm.nih.gov/16020725/.

674 Esson, H.J., Morriswood, B., Yavuz, S., Vidilaseris, K., Dong, G., and Warren, G. (2012) Morphology of 675 the trypanosome bilobe, a novel cytoskeletal structure. Eukaryot Cell 11: 761-772.

676 Field, M.C., and Carrington, M. (2009) The trypanosome flagellar pocket. Nat Rev Micro 7: 775-786 677 http://dx.doi.org/10.1038/nrmicro2221.

678 Fritz, M., Vanselow, J., Sauer, N., Lamer, S., Goos, C., Siegel, T.N., et al. (2015) Novel insights into RNP 679 granules by employing the trypanosome's microtubule skeleton as a molecular sieve. Nucleic Acids 680 Res 43: 8013-8032 https://pubmed.ncbi.nlm.nih.gov/26187993/.

681 Gallo, J.M., and Precigout, E. (1988) Tubulin expression in trypanosomes. Biol Cell 64: 137-143

682 https://pubmed.ncbi.nlm.nih.gov/3067795/. 
683 Gallo, J.M., Précigout, E., and Schrével, J. (1988) Subcellular sequestration of an antigenically unique 684 beta-tubulin. Cell Motil Cytoskeleton 9: 175-183 https://pubmed.ncbi.nlm.nih.gov/2452022/.

685 Gambarotto, D., Zwettler, F.U., Guennec, M. Le, Schmidt-Cernohorska, M., Fortun, D., Borgers, S., et 686 al. (2019) Imaging cellular ultrastructures using expansion microscopy (U-ExM). Nat Methods 16: 7168774 https://pubmed.ncbi.nlm.nih.gov/30559430/.

688 Gheiratmand, L., Brasseur, A., Zhou, Q., and He, C.Y. (2013) Biochemical characterization of the bi689 lobe reveals a continuous structural network linking the bi-lobe to other single-copied organelles in 690 Trypanosoma brucei. J Biol Chem 288: 3489-3499 https://pubmed.ncbi.nlm.nih.gov/23235159/.

691 Gorilak, P., Pružincová, M., Vachova, H., Olšinová, M., and Varga, V. (2021) Expansion microscopy 692 facilitates quantitative super-resolution studies of cytoskeletal structures in kinetoplastid parasites. 693 Open Biol 11: 210131 https://doi.org/10.1101/2021.04.20.440601.

694 Grigoryan, G., and Keating, A.E. (2008) Structural specificity in coiled-coil interactions. Curr Opin 695 Struct Biol 18: 477-483 https://pubmed.ncbi.nlm.nih.gov/18555680/.

696 Gull, K. (1999) The cytoskeleton of trypanosomatid parasites. Annu Rev Microbiol 53: 629-655 697 https://pubmed.ncbi.nlm.nih.gov/10547703/.

698 Hayes, P., Varga, V., Olego-Fernandez, S., Sunter, J., Ginger, M.L., and Gull, K. (2014) Modulation of a 699 cytoskeletal calpain-like protein induces major transitions in trypanosome morphology. I Cell Biol 700 206: 377-384.

701 Hilton, N.A., Sladewski, T.E., Perry, J.A., Pataki, Z., Sinclair-Davis, A.N., Muniz, R.S., et al. (2018) 702 Identification of TOEFAZ1-interacting proteins reveals key regulators of Trypanosoma brucei 703 cytokinesis. Mol Microbiol 109: 306-326 http://doi.wiley.com/10.1111/mmi.13986.

704 Hirokawa, N., and Noda, Y. (2008) Intracellular transport and kinesin superfamily proteins, KIFs: 705 Structure, function, and dynamics. Physiol Rev 88: 1089-1118.

706 Hirokawa, N., Noda, Y., Tanaka, Y., and Niwa, S. (2009) Kinesin superfamily motor proteins and

707 intracellular transport. Nat Rev Mol Cell Biol 10: 682-696

708 https://www.nature.com/articles/nrm2774.

$709 \mathrm{Hu}, \mathrm{L} ., \mathrm{Hu}, \mathrm{H}$. , and Li, Z. (2012) A kinetoplastid-specific kinesin is required for cytokinesis and for maintenance of cell morphology in Trypanosoma brucei. Mol Microbiol 83: 565-578 https://pubmed.ncbi.nlm.nih.gov/22168367/.

Ivens, A.C., Peacock, C.S., Worthey, E.A., Murphy, L., Aggarwal, G., Berriman, M., et al. (2005) The genome of the kinetoplastid parasite, Leishmania major. Science 309: 436-442 https://pubmed.ncbi.nlm.nih.gov/16020728/.

Jentzsch, J., Sabri, A., Speckner, K., Lallinger-Kube, G., Weiss, M., and Ersfeld, K. (2020) Microtubule polyglutamylation is important for regulating cytoskeletal architecture and motility in Trypanosoma brucei. J Cell Sci 133.

Kaurov, I., Vancová, M., Schimanski, B., Cadena, L.R., Heller, J., Bílý, T., et al. (2018) The Diverged Trypanosome MICOS Complex as a Hub for Mitochondrial Cristae Shaping and Protein Import. Curr Biol 28: 3393-3407.e5.

Kim, D.I., Birendra, K.C., Zhu, W., Motamedchaboki, K., Doye, V., and Roux, K.J. (2014) Probing nuclear pore complex architecture with proximity-dependent biotinylation. Proc Natl Acad Sci U S A 111: 2453-2461.

Kim, D.I., Jensen, S.C., Noble, K.A., Kc, B., Roux, K.H., Motamedchaboki, K., and Roux, K.J. (2016) An improved smaller biotin ligase for BiolD proximity labeling. Mol Biol Cell 27: 1188-1196. 
726

727

728

729

730

731

732

733

734

735

736

737

738

739

740

741

742

743

744

745

746

747

Kohl, L., Sherwin, T., and Gull, K. (1999) Assembly of the paraflagellar rod and the flagellum attachment zone complex during the Trypanosoma brucei cell cycle. J Eukaryot Microbiol 46: 105109 https://pubmed.ncbi.nlm.nih.gov/10361731/.

Kramer, S., Queiroz, R., Ellis, L., Webb, H., Hoheisel, J.D., Clayton, C., and Carrington, M. (2008) Heat shock causes a decrease in polysomes and the appearance of stress granules in trypanosomes independently of elF2 $\alpha$ phosphorylation at Thr169. J Cell Sci 121: 3002-3014 https://pubmed.ncbi.nlm.nih.gov/18713834/.

Lacomble, S., Vaughan, S., Gadelha, C., Morphew, M.K., Shaw, M.K., McIntosh, J.R., and Gull, K. (2009) Three-dimensional cellular architecture of the flagellar pocket and associated cytoskeleton in trypanosomes revealed by electron microscope tomography. J Cell Sci 122: 1081-1090 http://jcs.biologists.org/cgi/content/full/122/8/1081/DC1.

Lacomble, S., Vaughan, S., Gadelha, C., Morphew, M.K., Shaw, M.K., McIntosh, J.R., and Gull, K. (2010) Basal body movements orchestrate membrane organelle division and cell morphogenesis in Trypanosoma brucei. J Cell Sci 123: 2884-2891.

Li, Z., Umeyama, T., and Wang, C.C. (2008) The chromosomal passenger complex and a mitotic kinesin interact with the tousled-like kinase in trypanosomes to regulate mitosis and cytokines. PLoS One 3 https://pubmed.ncbi.nIm.nih.gov/19043568/.

Lott, K., Li, J., Fisk, J.C., Wang, H., Aletta, J.M., Qu, J., and Read, L.K. (2013) Global proteomic analysis in trypanosomes reveals unique proteins and conserved cellular processes impacted by arginine methylation. J Proteomics 91: 210-225 https://pubmed.ncbi.nlm.nih.gov/23872088/.

Marx, A., Hoenger, A., and Mandelkow, E. (2009) Structures of kinesin motor proteins. Cell Motil Cytoskeleton 66: 958-966 https://pubmed.ncbi.nIm.nih.gov/19530174/.

Moreira, B.P., Fonseca, C.K., Hammarton, T.C., and Baqui, M.M.A. (2017) Giant FAZ10 is required for flagellum attachment zone stabilization and furrow positioning in Trypanosoma brucei. J Cell Sci 130: 1179-1193.

Morgan, G.W., Goulding, D., and Field, M.C. (2004) The single dynamin-like protein of Trypanosoma brucei regulates mitochondrial division and is not required for endocytosis. J Biol Chem 279: 10692701 http://dx.doi.org/10.1074/jbc.M312178200.

Morriswood, B., Havlicek, K., Demmel, L., Yavuz, S., Sealey-Cardona, M., Vidilaseris, K., et al. (2013) Novel bilobe components in Trypanosoma brucei identified using proximity-dependent biotinylation. Eukaryot Cell 12: 356-367.

Poon, S.K., Peacock, L., Gibson, W., Gull, K., and Kelly, S. (2012) A modular and optimized single marker system for generating Trypanosoma brucei cell lines expressing T7 RNA polymerase and the tetracycline repressor. Open Biol 2: 110037 https://pubmed.ncbi.nlm.nih.gov/22645659/.

Pyrih, J., Rašková, V., Škodová-Sveráková, I., Pánek, T., and Lukeš, J. (2020) ZapE/Afg1 interacts with Oxa1 and its depletion causes a multifaceted phenotype. PLoS One 15: e0234918 https://pubmed.ncbi.nlm.nih.gov/32579605/.

Ralston, K.S., Lerner, A.G., Diener, D.R., and Hill, K.L. (2006) Flagellar motility contributes to cytokinesis in Trypanosoma brucei and is modulated by an evolutionarily conserved dynein regulatory system. Eukaryot Cell 5: 696-711 https://pubmed.ncbi.nIm.nih.gov/16607017/.

Redmond, S., Vadivelu, J., and Field, M.C. (2003) RNAit: An automated web-based tool for the selection of RNAi targets in Trypanosoma brucei. Mol Biochem Parasitol 128: 115-118.

Robinson, D.R., Sherwin, T., Ploubidou, A., Byard, E.H., and Gull, K. (1995) Microtubule polarity and 
dynamics in the control of organelle positioning, segregation, and cytokinesis in the trypanosome cell cycle. J Cell Bio/ 128: 1163-1172 https://pubmed.ncbi.nlm.nih.gov/7896879/.

Rotureau, B., Subota, I., and Bastin, P. (2011) Molecular bases of cytoskeleton plasticity during the Trypanosoma brucei parasite cycle. Cell Microbiol 13: 705-716.

Schenk, R., Bachmaier, S., Bringaud, F., and Boshart, M. (2021) Efficient flavinylation of glycosomal fumarate reductase by its own ApbE domain in Trypanosoma brucei. FEBS $J$ https://doi.org/10.1111/febs.15812 https://pubmed.ncbi.nlm.nih.gov/33755328/.

Schindelin, J., Arganda-Carreras, I., Frise, E., Kaynig, V., Longair, M., Pietzsch, T., et al. (2012) Fiji: An open-source platform for biological-image analysis. Nat Methods 9: 676-682 https://www.nature.com/articles/nmeth.2019.

Sheriff, O., Lim, L.F., and He, C.Y. (2014) Tracking the biogenesis and inheritance of subpellicular microtubule in Trypanosoma brucei with inducible YFP- $\alpha$-tubulin. Biomed Res Int 2014.

Sherwin, T., and Gull, K. (1989) Visualization of detyrosination along single microtubules reveals novel mechanisms of assembly during cytoskeletal duplication in trypanosomes. Cell 57: 211-221 https://pubmed.ncbi.nlm.nih.gov/2649249/.

Sherwin, T., Schneider, A., Sasse, R., Seebeck, T., and Gull, K. (1987) Distinct localization and cell cycle dependence of $\mathrm{COOH}$ terminally tyrosinolated $\alpha$-tubulin in the microtubules of Trypanosoma brucei brucei. J Cell Biol 104: 439-446 https://pubmed.ncbi.nlm.nih.gov/3546334/.

Sinclair, A.N., and Graffenried, C.L. de (2019) More than Microtubules: The Structure and Function of the Subpellicular Array in Trypanosomatids. Trends Parasitol 35: 760-777 https://pubmed.ncbi.nlm.nih.gov/31471215/.

Sunter, J.D., and Gull, K. (2016) The Flagellum Attachment Zone: 'The Cellular Ruler' of Trypanosome Morphology. Trends Parasito/ 32: 309-324 https://pubmed.ncbi.nlm.nih.gov/26776656/.

Urbaniak, M.D., Guther, M.L.S., and Ferguson, M. a J. (2012) Comparative SILAC proteomic analysis of Trypanosoma brucei bloodstream and procyclic lifecycle stages. PLoS One 7: e36619 http://www.pubmedcentral.nih.gov/articlerender.fcgi?artid=3344917\&tool=pmcentrez\&rendertype $=$ abstract.

Varga, V., Moreira-Leite, F., Portman, N., and Gull, K. (2017) Protein diversity in discrete structures at the distal tip of the trypanosome flagellum. Proc Natl Acad Sci U S A 114: E6546-E6555 https://www.pnas.org/content/114/32/E6546.

Wei, Y., Hu, H., Lun, Z.-R., and Li, Z. (2013) The Cooperative Roles of Two Kinetoplastid-Specific Kinesins in Cytokinesis and in Maintaining Cell Morphology in Bloodstream Trypanosomes. PLoS One 8: e73869 https://dx.plos.org/10.1371/journal.pone.0073869.

Wheeler, R.J., Gull, K., and Sunter, J.D. (2019) Coordination of the cell cycle in trypanosomes. Annu Rev Microbiol 73: 133-154 https://pubmed.ncbi.nlm.nih.gov/31500537/.

Wheeler, R.J., Scheumann, N., Wickstead, B., Gull, K., and Vaughan, S. (2013) Cytokinesis in Trypanosoma brucei differs between bloodstream and tsetse trypomastigote forms: implications for microtubule-based morphogenesis and mutant analysis. Mol Microbiol 90: 1339-1355 http://www.ncbi.nlm.nih.gov/pubmed/24164479.

Wickstead, B., Carrington, J.T., Gluenz, E., and Gull, K. (2010a) The expanded kinesin-13 repertoire of trypanosomes contains only one mitotic kinesin indicating multiple extra-nuclear roles. PLoS One 5: e0015020 https://pubmed.ncbi.nlm.nih.gov/21124853/.

Wickstead, B., Ersfeld, K., and Gull, K. (2002) Targeting of a tetracycline-inducible expression system 
812 to the transcriptionally silent minichromosomes of Trypanosoma brucei. Mol Biochem Parasitol 125:

813 211-6 http://www.ncbi.nlm.nih.gov/pubmed/12467990.

814 Wickstead, B., and Gull, K. (2006) A "Holistic" Kinesin Phylogeny Reveals New Kinesin Families and

815 Predicts Protein Functions. Mol Biol Cell 17: 1734-1743.

816 Wickstead, B., Gull, K., and Richards, T.A. (2010b) Patterns of kinesin evolution reveal a complex

817 ancestral eukaryote with a multifunctional cytoskeleton. BMC Evol Biol 10:

818 https://doi.org/10.1186/1471-2148-10-110.

819 Woods, A., Sherwin, T., Sasse, R., MacRae, T.H., Baines, A.J., and Gull, K. (1989) Definition of 820 individual components within the cytoskeleton of Trypanosoma brucei by a library of monoclonal 821 antibodies. J Cell Sci 93 ( Pt 3): 491-500 http://europepmc.org/abstract/MED/2606940.

822 Woodward, R., and Gull, K. (1990) Timing of nuclear and kinetoplast DNA replication and early

823 morphological events in the cell cycle of Trypanosoma brucei. J Cell Sci 95 ( Pt 1): 49-57

824 http://www.ncbi.nlm.nih.gov/pubmed/2190996.

825 Zhou, Q., An, T., Pham, K.T.M., Hu, H., and Li, Z. (2018) The CIF1 protein is a master orchestrator of

826 trypanosome cytokinesis that recruits several cytokinesis regulators to the cytokinesis initiation site.

827 J Biol Chem 293: 16177-16192 https://pubmed.ncbi.nlm.nih.gov/30171070/.

828 Zoltner, M., Pino, R.C. del, and Field, M.C. (2020) Sorting the Muck from the Brass: Analysis of

829 Protein Complexes and Cell Lysates. In Methods in Molecular Biology. Humana Press Inc., pp. 645-

830653 https://pubmed.ncbi.nlm.nih.gov/32221947/.

\section{FIGURE LEGENDS}

Fig. 1: Domain architecture of TbPH1 and TbKifX2. Schematic depiction includes phosphorylation and arginine methylation sites. The consensus Walker A motif is shown in between the two schemata for comparison of the respective motifs with in the kinesin motor domains of TbPH1 and TbKifX2. Key residues in ATP hydrolysis shown in red and mutations in purple. The likely inactive state of the TbPH1 'kinesin motor domain' is highlighted by striped pattern. CC: coiled coil domain, PH: pleckstrin homology domain, HDL: homeodomain-like fold.

Fig. 2: TbPH1-V5 fractionates with the cytoskeleton. (A) Western blot of-trypanosome cell fractions. Fractionation procedure is summarized in S1 Fig. Antibodies used were anti-V5 and anti-SCD6 (Kramer et al., 2008). T: total lysate, SN: supernatant, P: pellet. (B) IFA of on an aliquot of fraction P2 placed on slides for fluorescence microscopy. Cells were labelled with anti-V5 antibody (white) and DAPI (magenta). The scale bar corresponds to $5 \mu \mathrm{m}$.

Fig. 3: TbPH1 interacts with TbKifX2, a kinetoplastid-specific kinesin. (A) Western blot verifying immunoprecipitation of TbPH1-V5. The blot was probed with anti-V5 and anti- $\alpha$-tubulin antibodies. The parental cell line Sm OxP9 was used as a control. T: total lysate, SN3: supernatant 3, FT: flow through, E: elution. (B) SyproRuby-stained gel of elution fractions of TbPH1-V5 IP and mock control (SmOxP9). B1 and B2: bands excised and by mass spectrometry identified to be TbPH1 and TbKifX2, respectively. Asterisks: band corresponding to denatured immunoglobulin light chain that was incidentally eluted. (C) Western blot showing interaction of TbPH1-V5 and TbKifX2-HA. TbKifX2-HA was immunoprecipitated in the same way as PH1-V5. T: total lysate, SN: supernatant, P: pellet, FT: flow through, E: elution. (D) IFA on whole cells detecting TbPH1-V5 (white) and counterstained with 853 DAPI to visualize DNA (magenta). Arrowheads denote increased signal in the area along the proximal 854 part of the flagellum. Asterisks demark an increased signal at the anterior cell end. Merge of DAPI 
855 and Phase contrast images shown on bottom. Scale bar, $10 \mu \mathrm{m}$. (E) IFA on whole cells detecting

856 TbKifX2-HA (white). Images depicted as in D.

857 Fig. 4: The proximal proteome of TbPH1. (A) IFA on whole cells showing localisation of TbPH1-

858 BiolD2-HA (white) and biotinylated proteins (white) and counterstained with DAPI (magenta).

859 Arrowheads denote signal in vicinity of kinetoplast, near the proximal part of the flagellum. DIC on

860 right to show observed cell. Scale bar, $5 \mu \mathrm{m}$. (B) IFA as in A of parental cell line lacking TbPH1-BiolD2-

861 HA. (C) Western blot (top panel) and fluorescently-detected proteins resolved on SDS-PAGE as a

862 loading control (bottom panel, stain-free gel) of a representative BiolD experiment. The blot was

863 probed with anti-HA to confirm the presence of TbPH1-BiolD2-HA in the respective fractions. E:

864 extract, SN: supernatant, F: flow through, B: boiled beads. (D) Volcano plot with -10 log t-test p value

865 plotted against the t-test difference between TbPH1-BiolD2-HA sample and mock (SmOxP9 cells)

866 from three biological replicates. Statistically significant hits are found above the curve in the top

867 right quadrant and their identity is indicated. Accession numbers are given with additional

868 annotations in parentheses; these are color coded based on their localization determined by TrypTag

869 (Dean et al., 2017). (E) Heat map of SAINTq score (i.e. P value) of proteins interacting with TOEFAZ1

870 (Hilton et al., 2018), the relative enrichment of proteins also found in the TbPH1 proximal proteome

871 are indicated. a:Tb927.3.2490 (TbPH1), b: Tb927.8.1950 (ApbE-like domain), c: Tb927.9.15470

872 (TbKifX2), d: Tb927.3.4720/60 (DLP1/2). PG, protein groups. (F) Venn diagram comparing the

873 proximity proteome of TbPH1 with those of the TOEFAZ (as depicted in E), the hook complex protein

874 TbMorn1 (all 79 biotinylated proteins (Morriswood et al., 2013)), and the 11 high confidence

875 proteins in the TbSpef1, a MtQ binding protein (Dong et al., 2020). Proteins exclusive to the TbPH1

876 proximity proteome are highlighted in green while magenta highlights those that are found to also

877 be in proximity with TOEFAZ.

878 Fig. 5: Localization of cytoskeleton-associated TbKifX2 and TbPH1. (A) IFA on extracted cytoskeletons

879 probing localisation of TbPH1-V5 (green) and TbKifX2-HA (white). (B) IFA on extracted cytoskeletons

880 probing co-localisation of TbKifX2-HA (white) with the FAZ (green), the latter labelled with L3B2

881 antibody. (C) IFA on extracted cytoskeletons probing co-localisation of TbKifX2-HA (white) with basal

882 bodies (green), the latter labelled with YL1/2 antibody (D) IFA on extracted cytoskeletons probing

883 co-localisation of TbKifX2-HA (white) with the MtQ (green), the latter labelled with $1 \mathrm{~B} 41$ antibody. In

884 all panels, merge images depict co-localization in magenta and DIC on right showing observed

885 extracted cytoskeleton. Scale bar, $5 \mu \mathrm{m}$.

886 Fig 6: TbKifX2 and TbPH1 localize to the MtQ. Ultrastructure expansion microscopy images depicted

887 as 3D projections (A-D) and representative confocal image sections used to make projections (E-F) of

888 T. brucei expressing TbPH1-V5 and TbKifX2-HA. (A) 3D reconstruction of the area of the cell in the

889 vicinity of the basal body and flagellum exit from the flagellar pocket looking from outside the MT

890 corset. Top shows signal from anti-V5 (green) and anti-acetylated $\alpha$-tubulin (white) antibodies.

891 Bottom is the same image of anti-acetylated $\alpha$-tubulin signal only with relevant structures marked.

892 Tick marks at $5 \mu \mathrm{m}$ increments (A-C). (B) Same as A but showing anti-HA antibody signal (green) and

893 a view shown from inside the MT corset. (C) 3D reconstruction of the posterior part of the cell.

894 Signal colors correspond to A. (D) 3D reconstruction of whole dividing T. brucei cell. Signal colors

895 correspond to B. Box highlights region of interest shown in F. Tick marks at $10 \mu \mathrm{m}$ increments. (E)

896 Confocal images from the vicinity of the basal body showing from left to right signal of anti-V5 and

897 anti-acetylated $\alpha$-tubulin antibodies(both white) plus an overlay of both signals with V 5 signal in

898 green. Left image shows $5 \mu \mathrm{m}$ scale bar. Middle image marks relevantstructures. (F) Same as in E

899 except two sections being shown, focusing on new (Top) and old MtQ (Bottom), and the left images 
900

901

902

903

904

905

906

907

908

909

910

911

912

913

914

915

916

917

918

919

920

921

922

923

924

925

926

927

928

929

930

931

932

933

934

935

936

937

938

939

940

941

942

943

showing anti-HA antibody signal. Solid arrowheads point to overlay of epitope antibody signal and MtQ. Hollow arrowheads point to representative epitope antibody signals found in the cytosol.

Fig. 7: Depletion of TbPH1 and TbKifX2 affects posterior end remodelling. (A) Bar chart showing population doubling times for TbPH1, TbKifX2 and TbPH1/TbKifX2 depletion cell lines. -/+: -/+ doxycycline to induce RNAi, the average difference in hours from three experiments is shown above the respective bars. (B) Western blot of cellular fractionation experiment following TbKifX2 RNAi. The blot was probed with anti-HA (to detect TbKifX2), anti-V5 (to detect TbPH1) and anti- $\alpha$-tubulin as a loading control. WCL: whole cell lysate. (C) Phase contrast images of TbPH1/TbKifX2 RNAi cells. + tet: induced for 5 days. The scale bar corresponds to $5 \mu \mathrm{m}$. Arrows indicate morphological defects. (D) Scanning electron microscopy of TbPH1/TbKifX2 RNAi cells. + tet: induced for 5 days. Arrows pointing to posterior end protrusions. The scale bar corresponds to $10 \mu \mathrm{m}$.

S1 Fig.: Schematic depiction of microtubule sieving technique. According to (Fritz et al., 2015).

S2 Fig.: Schematic depiction of proximity-dependent biotinylation (BiolD). According to (Morriswood et al., 2013). Only steps in black were performed in our study.

S3 Fig.: Wider field of view of multiple extracted cytoskeletons co-localizing TbKifX2 and TbPH1 to basal body (C), FAZ (D) and MtQ (E). Images depicted as in Fig 5 with scale bar corresponding to 5 $\mu \mathrm{m}$. (A) Co-localization (merge, magenta) of TbPH1-V5 (green) and TbKifX2-HA (white). (B) Parental cell line lacking TbPH1-V5 and TbKifX2-HA, incubated with antibodies recognizing V5 and HA epitopes used to acquire other IFA images.

S4 Fig.: Ultrastructure expansion microscopy of a cell labelled with anti-ClpGM6 (to detect the FAZ, green) and anti-acetylated $\alpha$ tubulin antibody C3B9 (grey). Only the region around the pocket and flagellum exit shown.

S5 Fig.: TbPH1/TbKifX2 RNAi. (A) Growth curves of TbPH1 and TbKIfX2 RNAi cell lines. Filled circles: TbKifX2 - tet, open circles: TbKIfX2 + tet, filled triangles: TbPH1 - tet, open triangles: TbPH1 + tet. Standard deviation of measurements at each time point $(n=3)$ is not visible at this scale. Insets show western blots probed with anti-HA (to detect TbKifX2), anti-V5 (to detect TbPH1) and anti- $\alpha$-tubulin as a loading control. (B) Growth curve of TbPH1/TbKifX2 RNAi cell line. Filled circles: TbPH1/TbKifX2 - tet, open circles: TbPH1/TbKifX2 + tet. Standard deviation of measurements at each time point $(n=3)$ is not visible at this scale. Inset depicts western blot showing depletion of TbPH1/TbKifX2. Samples were taken at the same time as the growth curve in $B$ was performed. The blot was probed with anti-HA (to detect TbKifX2), anti-V5 (to detect TbPH1) and anti- $\alpha$-tubulin as a loading control. (C) Bar chart depicting different cell cycle phases during TbPH1/TbKifX2 RNAi time course. DAPI counts were performed in triplicate with at least 200 cells counted per time point. $\mathrm{N}$ : nucleus, $\mathrm{K}$ : kinetoplast. (D) IFA of TbPH1/TbKifX2 RNAi cells. + tet: induced for 5 days. Extracted cytoskeletons were labelled with L3B2 (recognising the FAZ filament, white), mAB 1B41 (recognising the MtQ, white) and DAPI (magenta). Scale bar, $5 \mu \mathrm{m}$.

S6 Fig.: Transmission electron microscopy and IFA of TbPH1/TbKifX2 RNAi cell line. Cells were induced for 5 days. (A) Image depicting posterior end protrusions (arrow). Scale bar, $1 \mu \mathrm{m}$. (B) Closeup of protrusion encapsulated by microtubule corset (arrowheads). The scale bar corresponds to 500 $\mathrm{nm}$. (C) IFA on cytoskeletons probing effects of TbPH1/TbKifX2 depletion post-translational modifications of tubulin. Cells were counterstained with GT335 (red, staining glutamyl side chains) and YL1/2 (green, staining tyrosinated $\alpha$-tubulin). The scale bar corresponds to $5 \mu \mathrm{m}$. (D) Western blots taken after 3 to 5 days (d) of growth in presence (+) or absence (-) of doxycycline probed with antibodies recognizing GT335, YL1/2 and $\alpha$-tubulin, the last as a loading control. 
bioRxiv preprint doi: https://doi.org/10.1101/2021.09.29.462327; this version posted November 23, 2021. The copyright holder for this preprint (which was not certified by peer review) is the author/funder, who has granted bioRxiv a license to display the preprint in perpetuity. It is made available under aCC-BY 4.0 International license.

944 S1 Dataset: Mass spectrometry analysis of excised bands B1 and B2 from Fig. 3B.

945 S2 Dataset: Mass spectrometry data of TbPH1 BiolD experiment. Data with and without imputation and filtered for Andromeda scores $>20$ and presence of $>1$ peptide, which was used to generate the volcano plot in Fig. 4D. 
bioRxiv preprint doi: $\mathrm{https}$ //doi.org/10.1101/2021.09.29.462327; this version posted November 23, 2021. The copyright holder for this preprint (which was not certified by peer review) is the author/funder, who has granted bioRxiv a license to display the preprint in perpetuity. It is made available under aCC-BY 4.0 International license.

\section{Fig. 1}

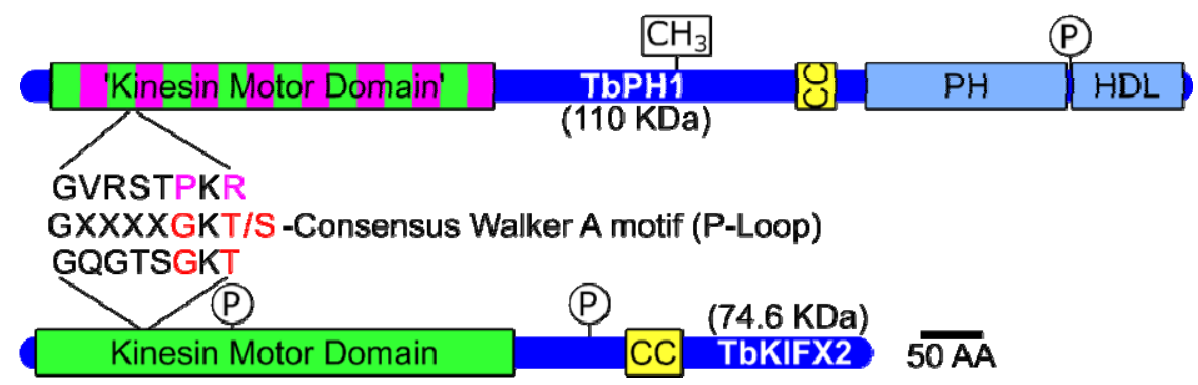

972

973

974

975

976

977

978

979

980

981

982

983

984

985

986

987

988

989

990

991

992

993

994

995

996 
bioRxiv preprint doi: https://doi.org/10.1101/2021.09.29,462327; this version posted November 23, 2021. The copyright holder for this preprint (which was not certified by peer review) is the author/funder, who has granted bioRxiv a license to display the preprint in perpetuity. It is made available under aCC-BY 4.0 International license.

Fig. 2

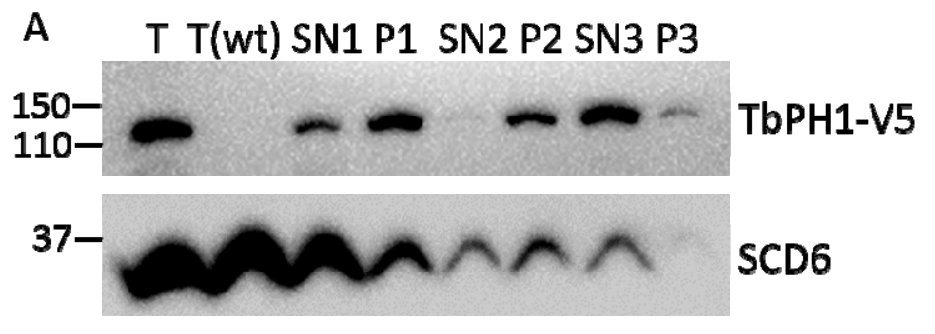

997

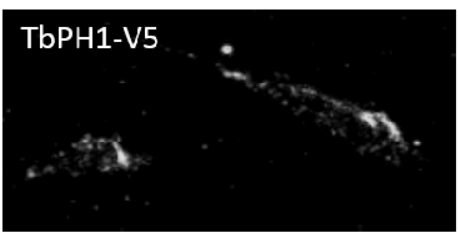

\section{DAPI}
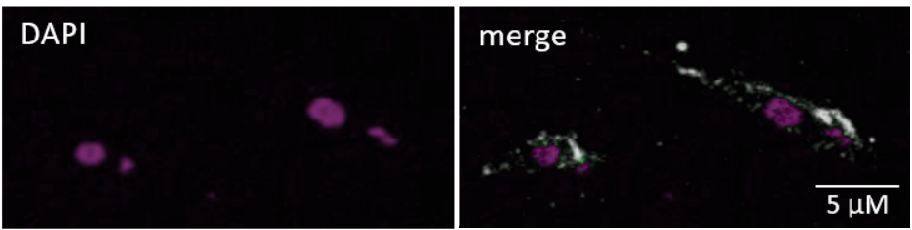

998

999

1000

1001

1002

1003

1004

1005

1006

1007

1008

1009

1010

1011

1012

1013

1014

1015

1016

1017

1018

1019 
bioRxiv preprint doi: https://doi.org/10.1101/2021.09.29.462327; this version posted November 23, 2021. The copyright holder for this preprint (which was not certified by peer review) is the author/funder, who has granted bioRxiv a license to display the preprint in perpetuity. It is made available under aCC-BY 4.0 International license.

Fig. 3
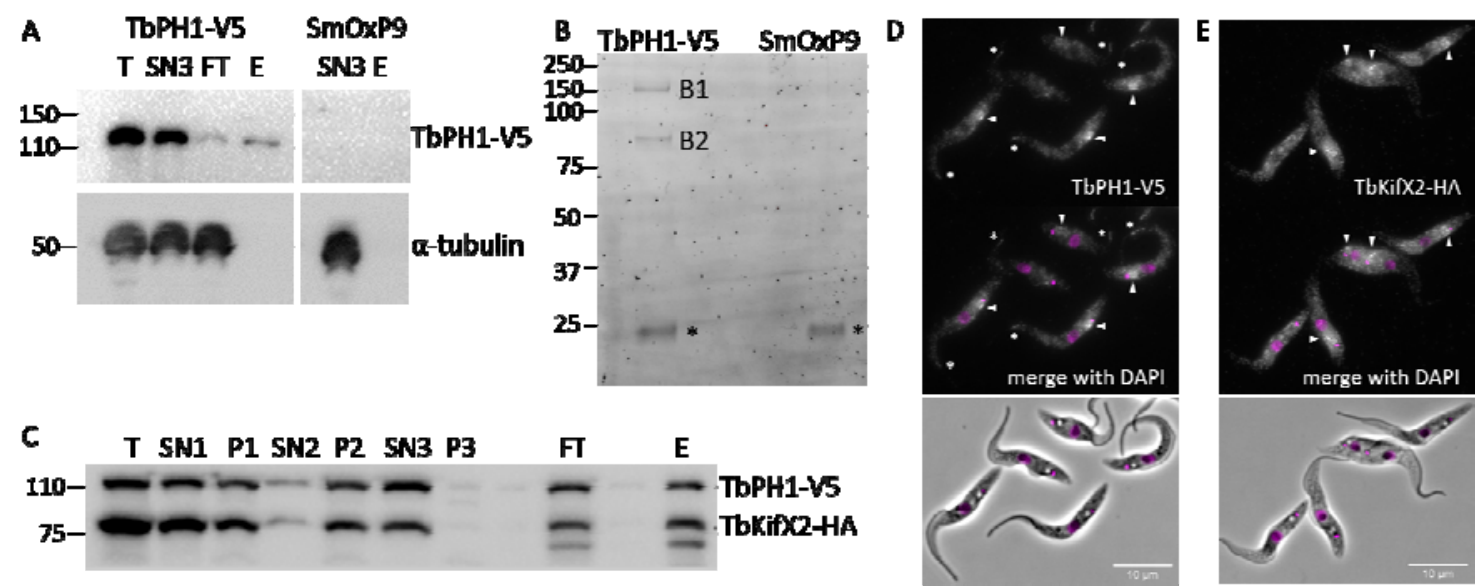

1021

1024

1025

1026

1027

1028

1029

1030

1031

1032

1033

1034

1035

1036

1037

1038

1039

1040

1041

1042 
bioRxiv preprint doi: https://doi.org/10.1101/2021.09.29.462327; this version posted November 23, 2021. The copyright holder for this preprint (which was not certified by peer review) is the author/funder, who has granted bioRxiv a license to display the preprint in perpetuity. It is made available under aCC-BY 4.0 International license.

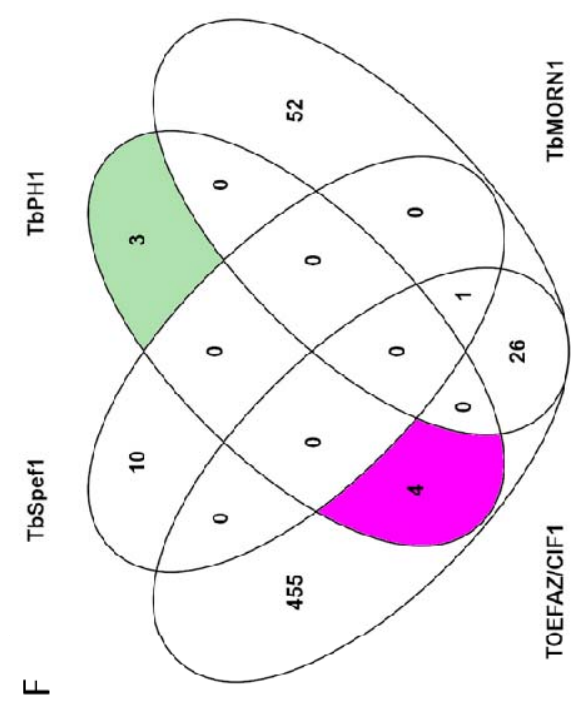

\section{谤}

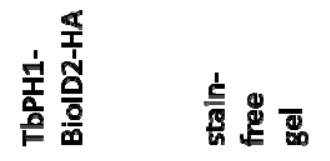

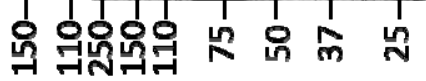
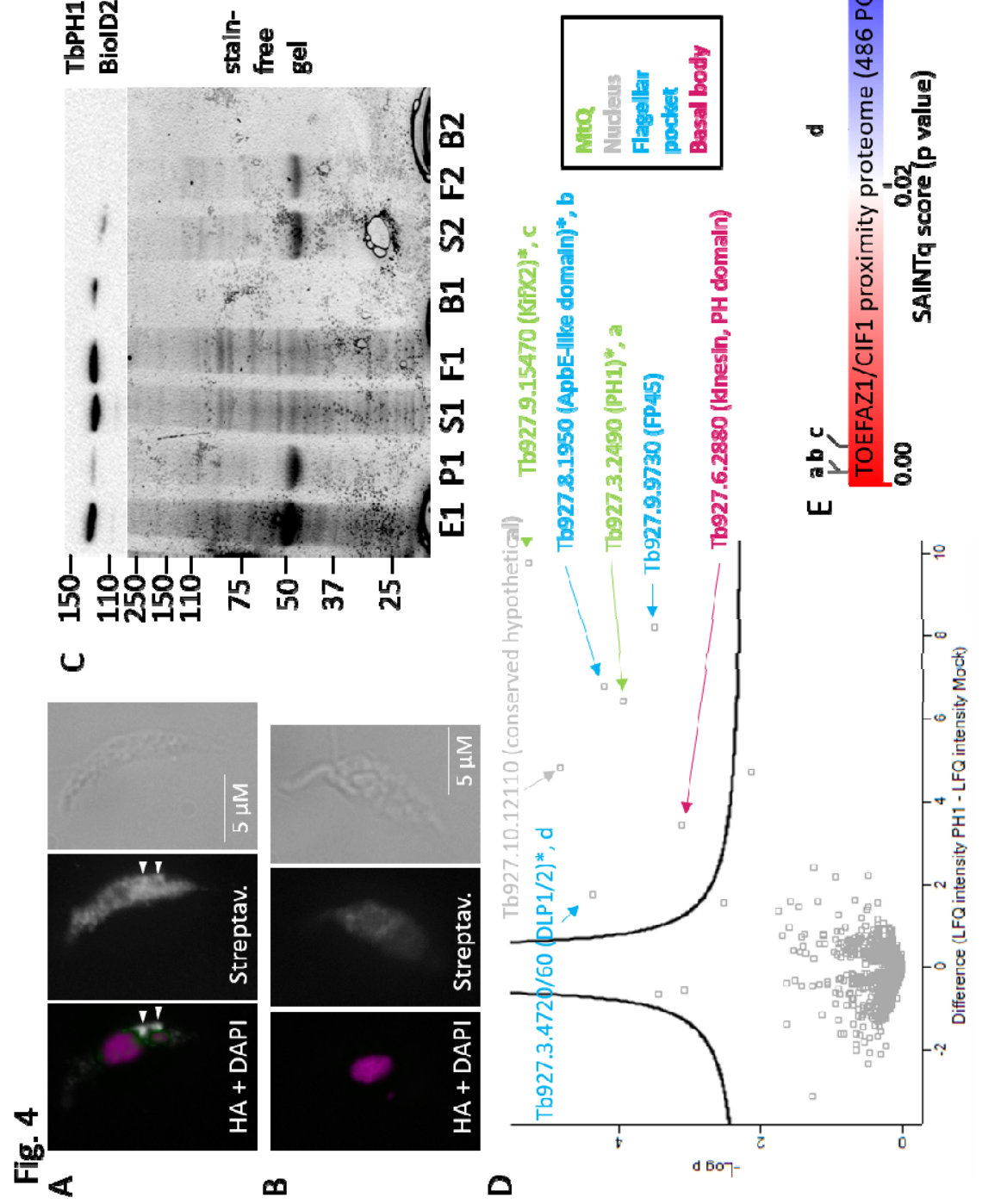
bioRxiv preprint doi: https://doi.org/10.1101/2021.09.29.462327; this version posted November 23, 2021. The copyright holder for this preprint (which was not certified by peer review) is the author/funder, who has granted bioRxiv a license to display the preprint in perpetuity. It is made available under aCC-BY 4.0 International license.

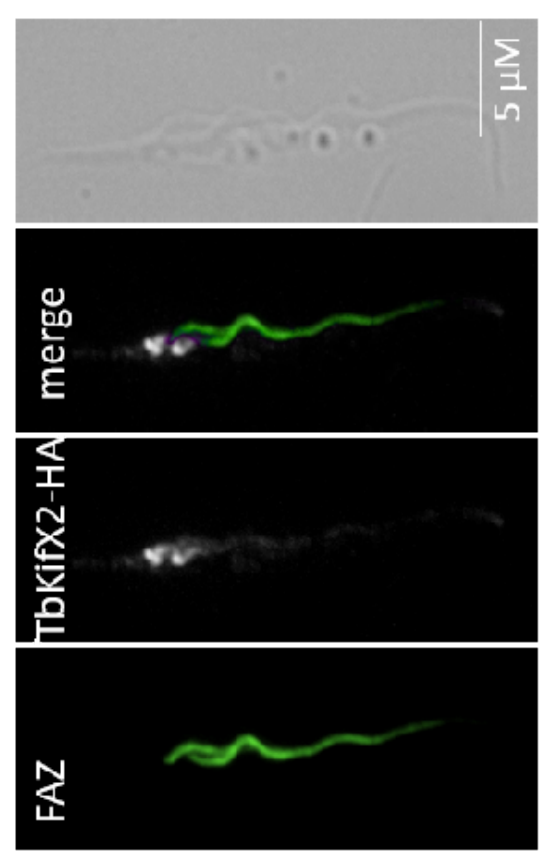

E
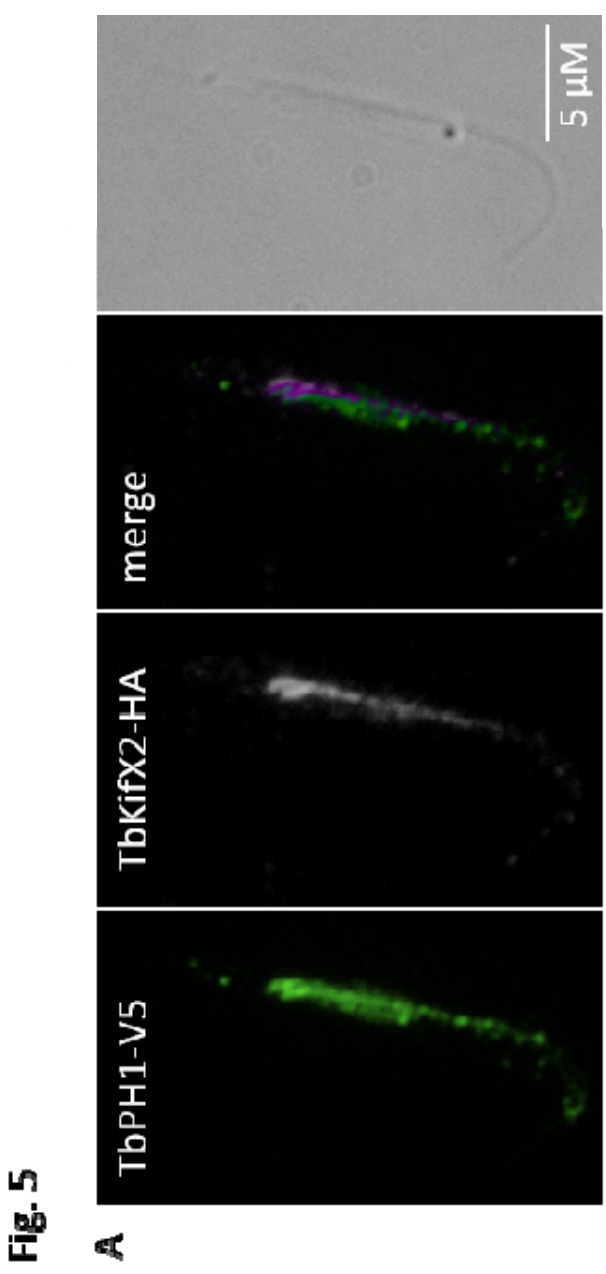

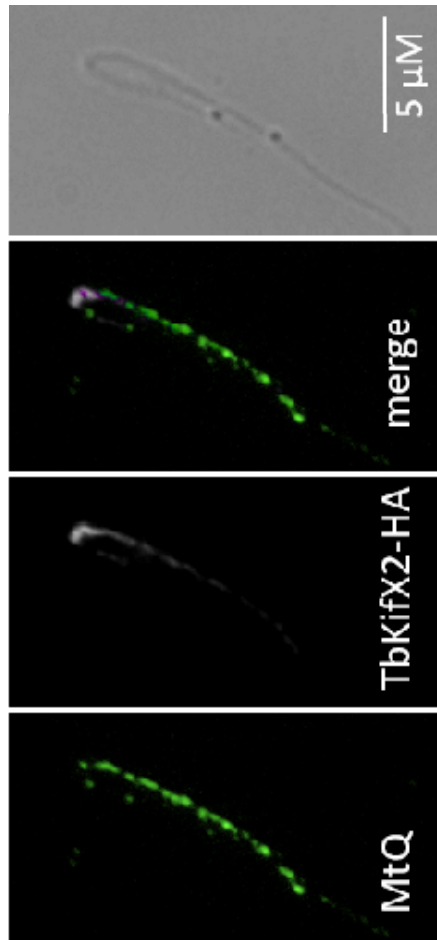

○

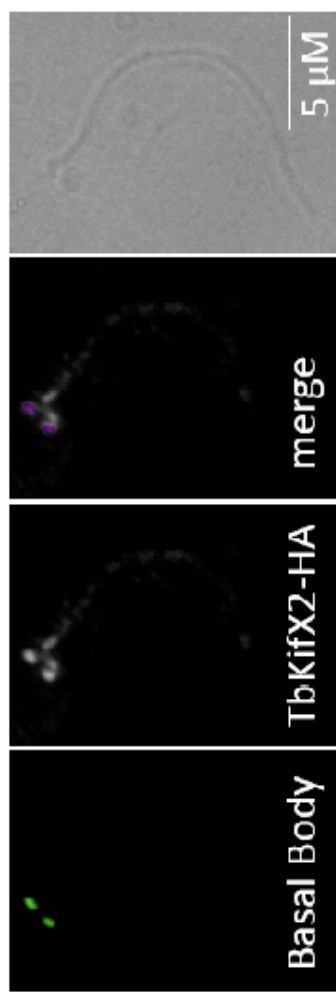

$\omega$ 
bioRxiv preprint doi: https://doi.org/10.1101/2021.09.29.462327; this version posted November 23, 2021. The copyright holder for this preprint (which was not certified by peer review) is the author/funder, who has granted bioRxiv a license to display the preprint in perpetuity. It is made available under aCC-BY 4.0 International license.
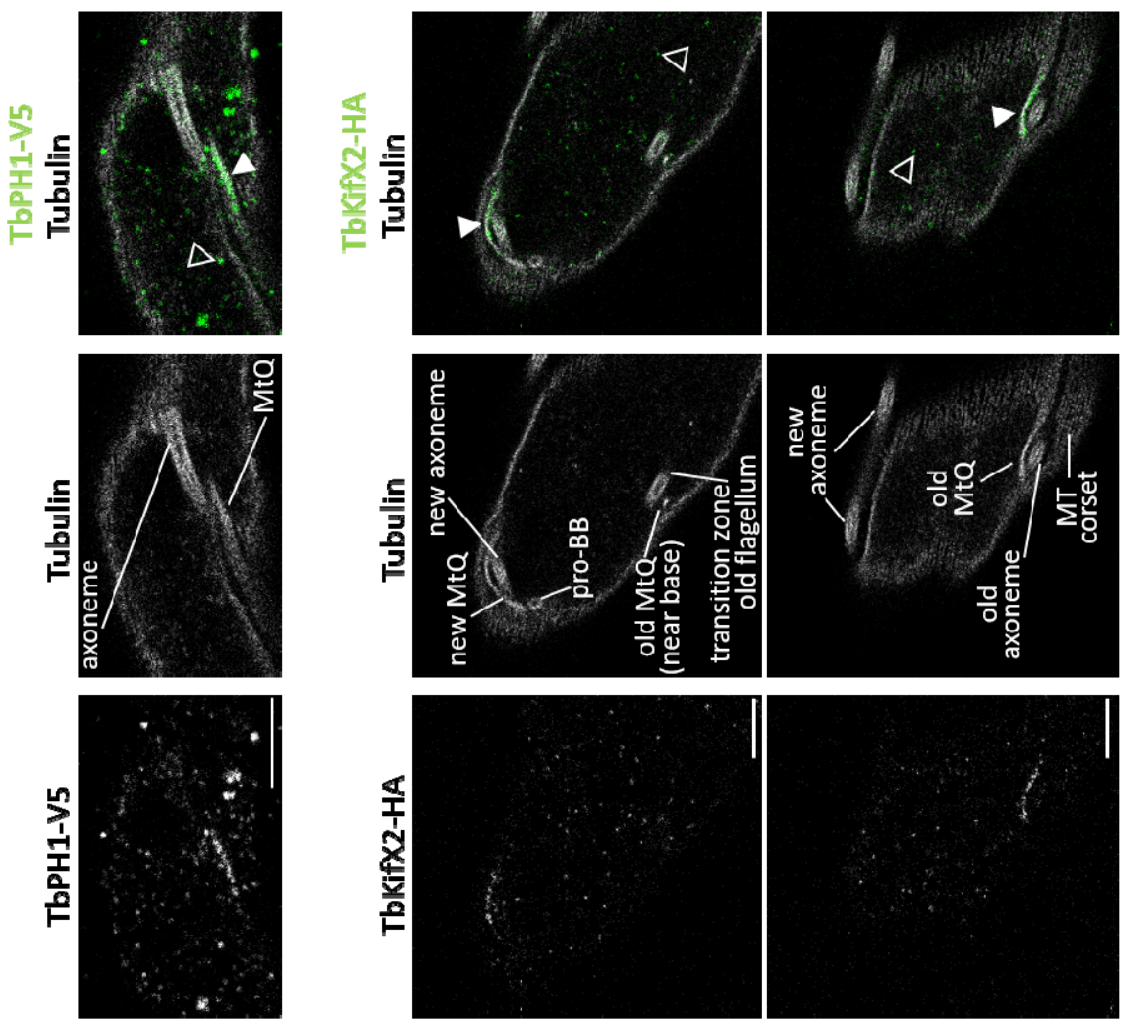

ш

느
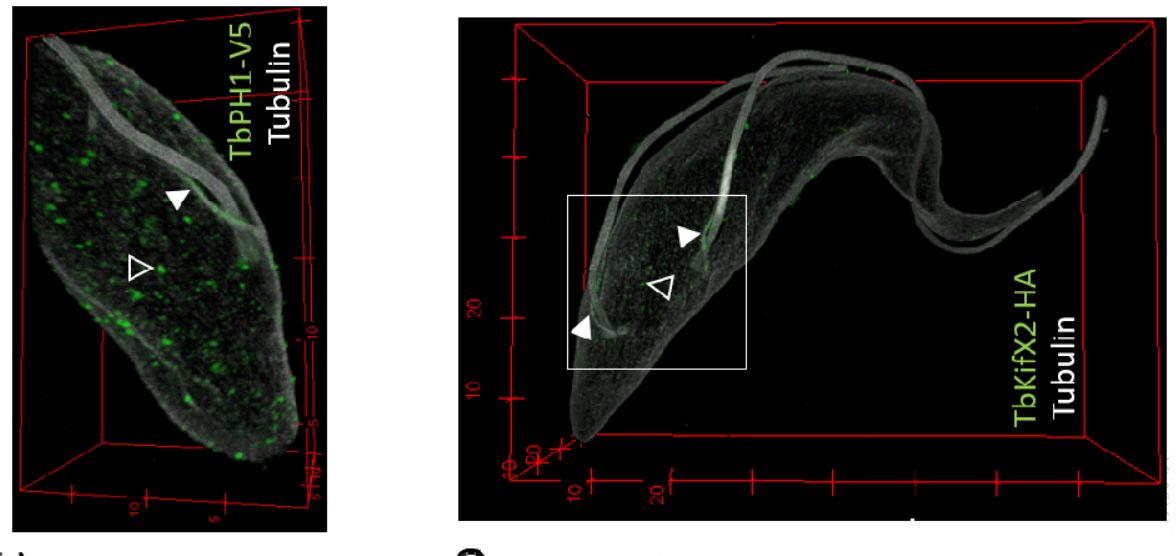

0
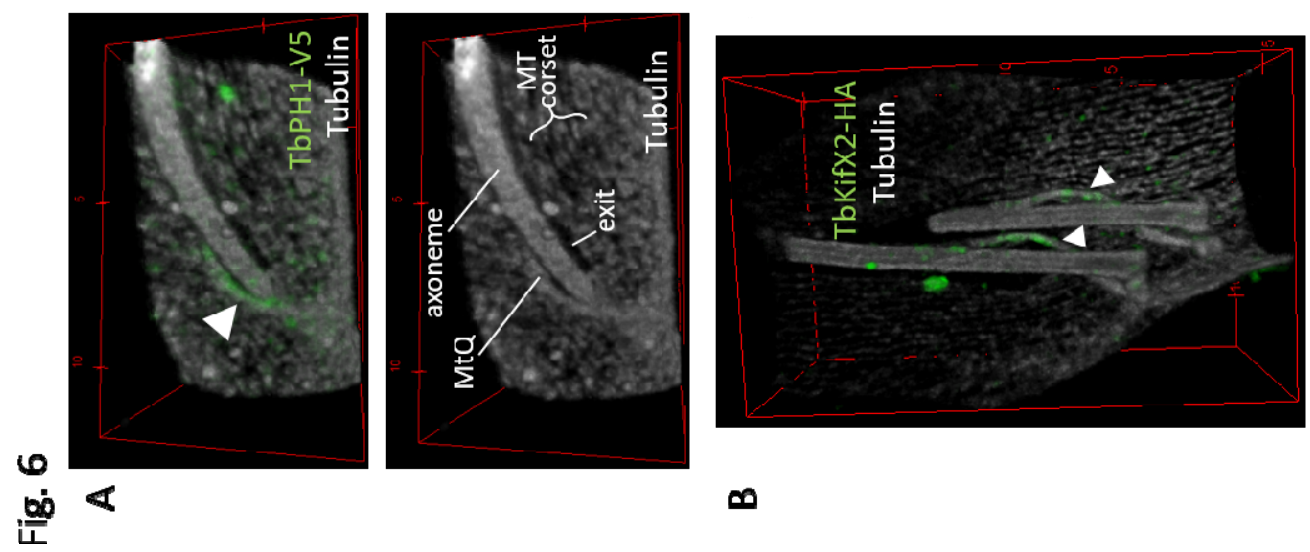
bioRxiv preprint doi: https://doi.org/10.1101/2021.09.29,462327; this version posted November 23, 2021. The copyright holder for this preprint (which was not certified by peer review) is the author/funder, who has granted bioRxiv a license to display the preprint in perpetuity. It is made available under aCC-BY 4.0 International license.

Flg. 7
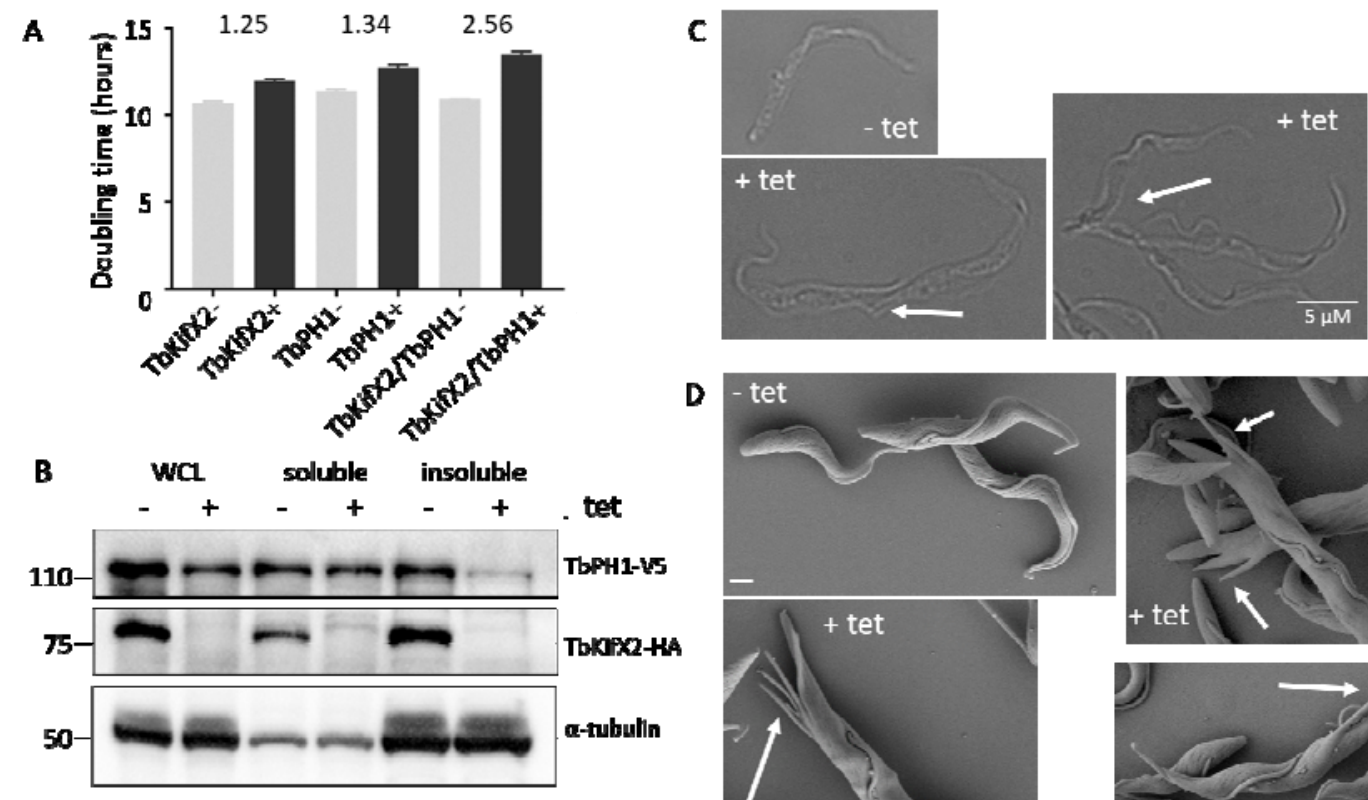

D

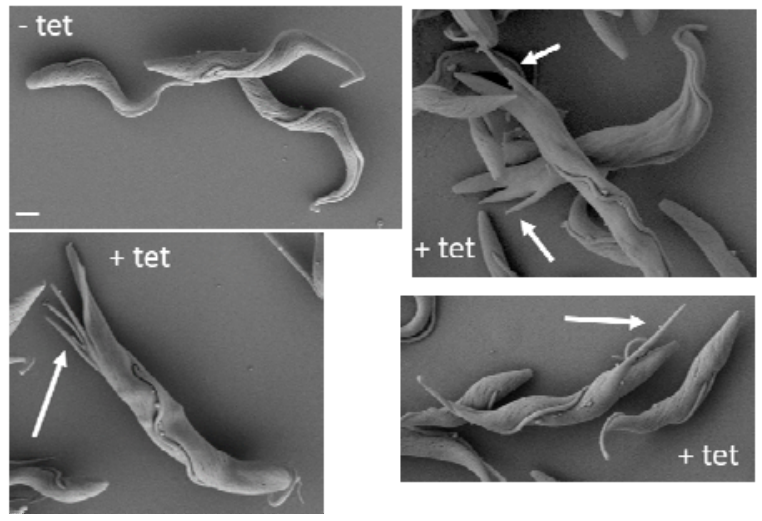

1049

1050

1051

1052

1053

1054

1055

1056

1057

1058

1059

1060

1061

1062

1063

1064

1065 
bioRxiv preprint doi: https://doi.org/10.1101/2021.09.29.462327; this version posted November 23, 2021. The copyright holder for this preprint (which was not certified by peer review) is the author/funder, who has granted bioRxiv a license to display the preprint in perpetuity. It is made available under aCC-BY 4.0 International license.

Suppl. Fg. 1

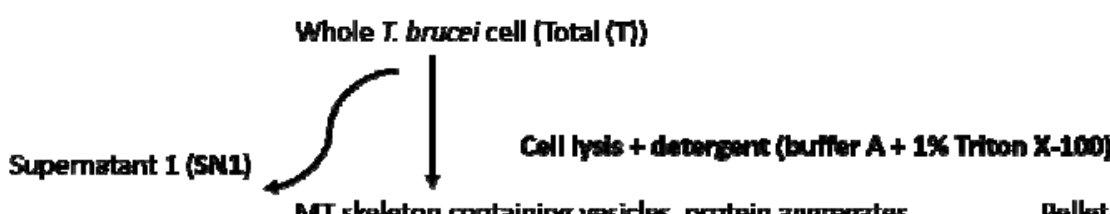

MT skeleton containing vesides, protein aggregates,

Pellet (P1)

nudei, kinetoplasts and flagella with associated structures

Supematant 1 (SNZ)

MT skeleton containing vesides, proteln aggregates,

Pellet (P2)

nuclel, kinetoplasts and flagella wth assoclated structures

Supematant 1 (SN3) Disruption of the cytosteleteon (buffer A + 1\% Thton X-100 + 300 mM NaC)

1066 assoclated structures

1067

1068

1069

1070

1071

1072

1073

1074

1075

1076

1077

1078

1079

1080

1081

1082

1083

1084

1085

1086 
bioRxiv preprint doi: https://doi.org/10.1101/2021.09.29.462327; this version posted November 23, 2021. The copyright holder for this preprint (which was not certified by peer review) is the author/funder, who has granted bioRxiv a license to display the preprint in perpetuity. It is made available under aCC-BY 4.0 International license.

Suppl. Fig. 2

1087

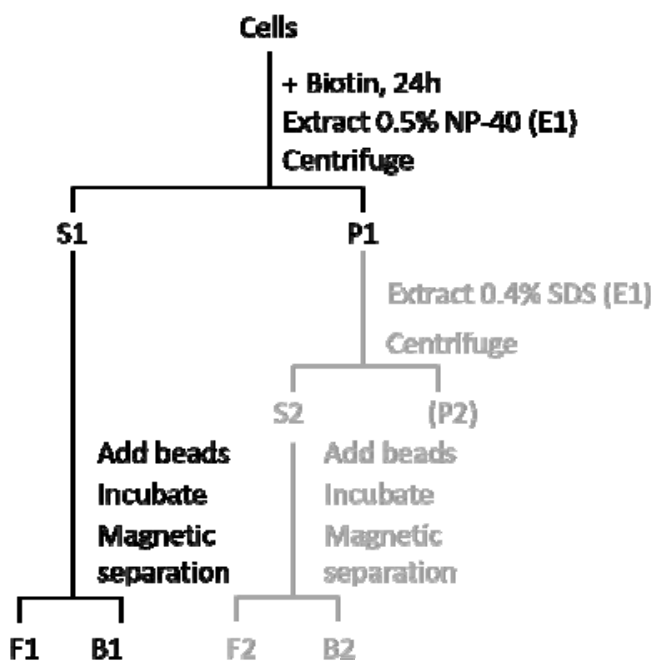

1088

1089

1090

1091

1092

1093

1094

1095

1096

1097

1098 
bioRxiv preprint doi: https://doi.org/10.1101/2021.09.29.462327; this version posted November 23, 2021. The copyright holder for this preprint (which was not certified by peer review) is the author/funder, who has granted bioRxiv a license to display the preprint in perpetuity. It is made available under aCC-BY 4.0 International license.

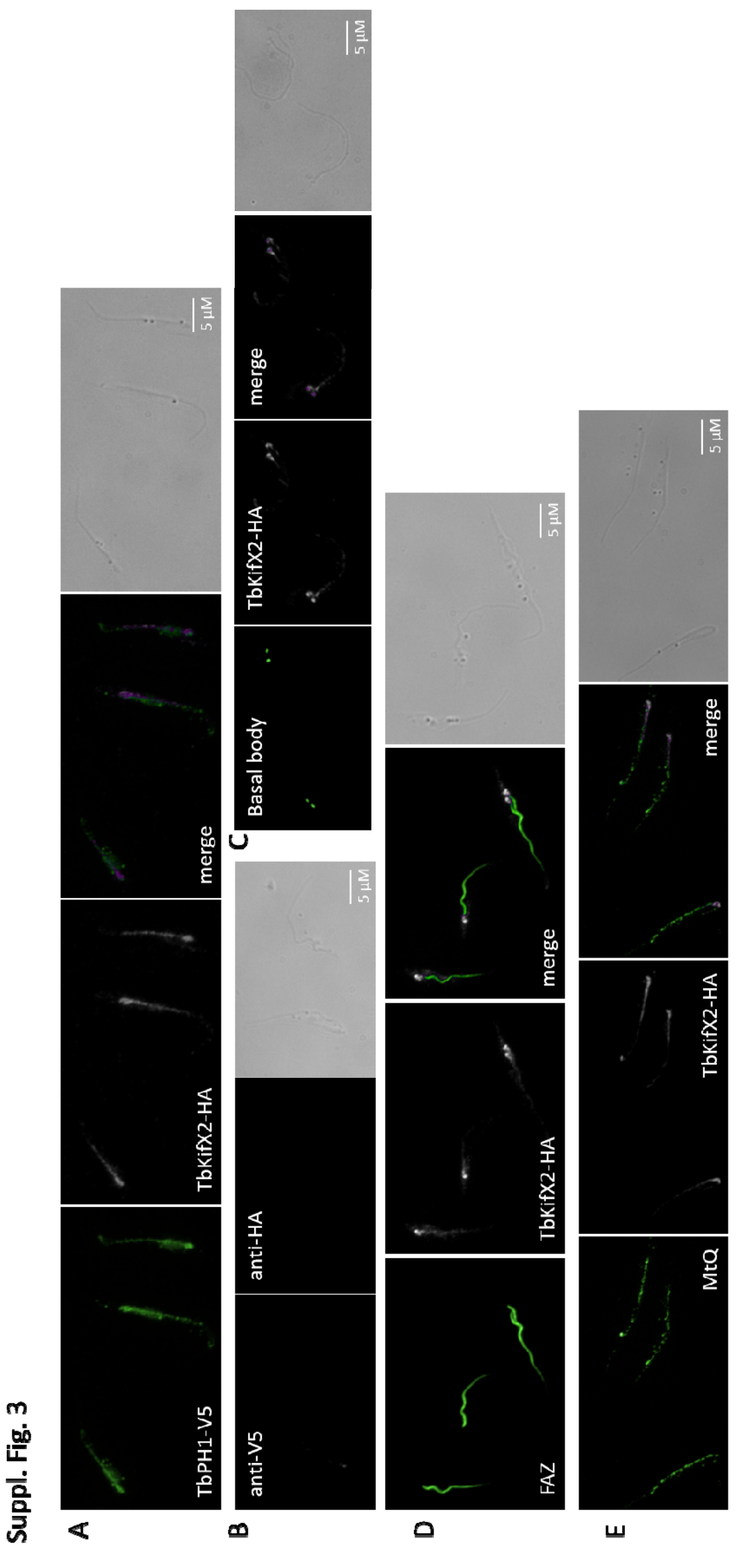


bioRxiv preprint doi: https://doi.org/10.1101/2021.09.29.462327; this version posted November 23, 2021. The copyright holder for this preprint (which was not certified by peer review) is the author/funder, who has granted bioRxiv a license to display the preprint in perpetuity. It is made available under aCC-BY 4.0 International license.

\section{Suppl. Fig. 4}

1100

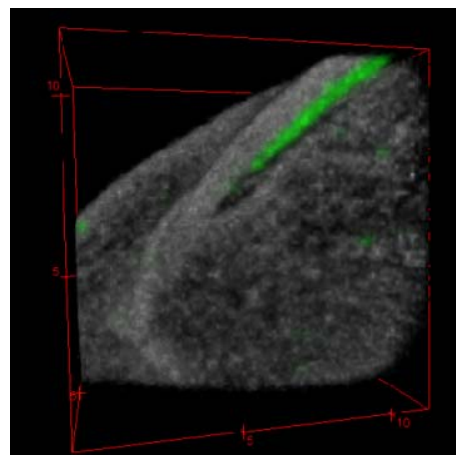

1101

1102

1103

1104

1105

1106

1107

1108

1109

1110

1111

1112

1113

1114

1115

1116

1117

1118

1119

1120

1121

1122

1123

1124

1125 
bioRxiv preprint doi: $\mathrm{https}$ //doi.org/10.1101/2021.09.29.462327; this version posted November 23, 2021. The copyright holder for this preprint (which was not certified by peer review) is the author/funder, who has granted bioRxiv a license to display the preprint in perpetuity. It is made available under aCC-BY 4.0 International license.

1126

Suppl. Fig. 5

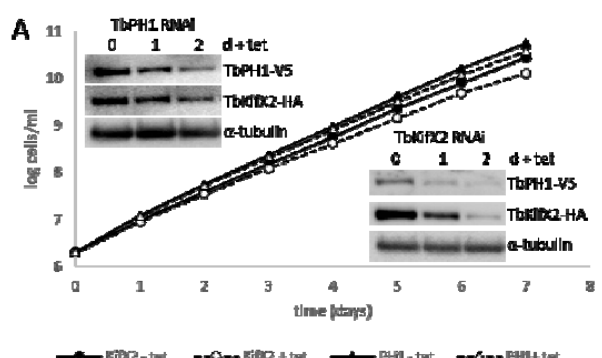

$c$

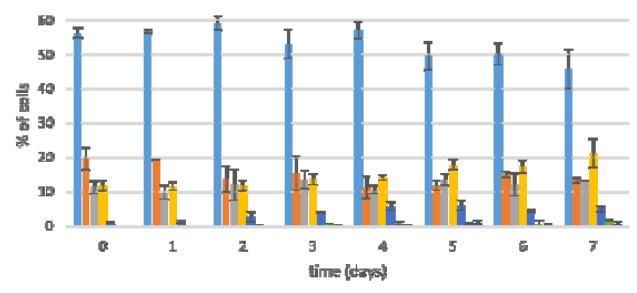

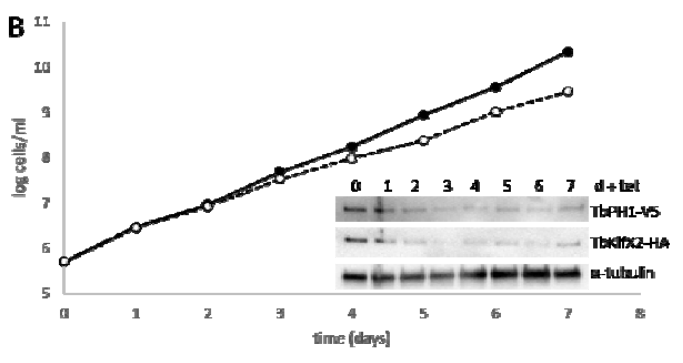

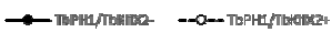

D

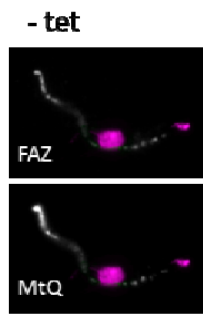

+ tet

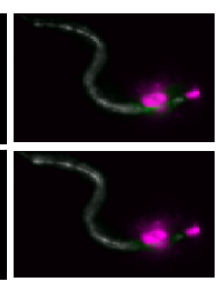

+ tet

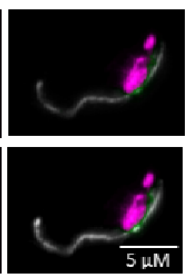


bioRxiv preprint doi: https://doi.org/10.1101/2021.09.29.462327: this version posted November 23, 2021. The copyright holder for this preprint (which was not certified by peer review) is the author/funder, who has granted bioRxiv a license to display the preprint in perpetuity. It is made available under aCC-BY 4.0 International license.

\section{Suppl. Flg. 6}

A

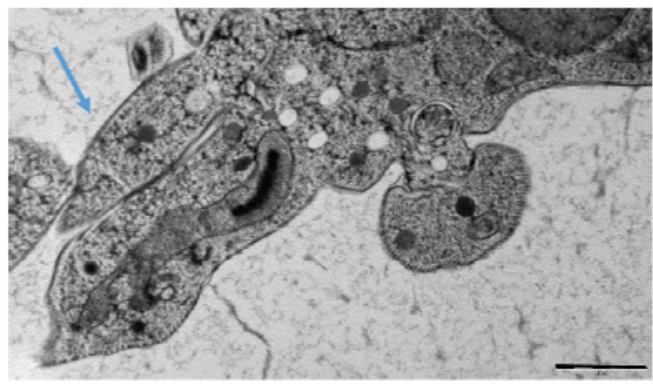

B

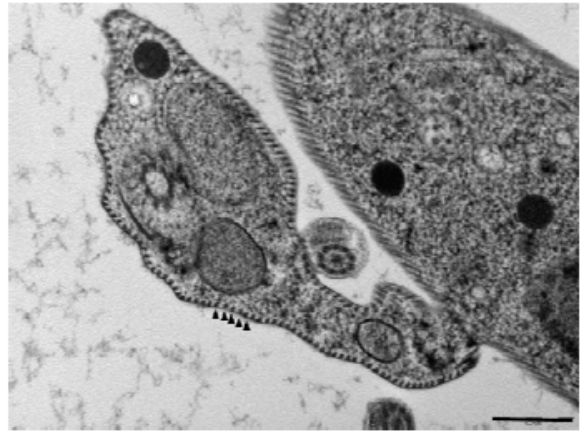

C.
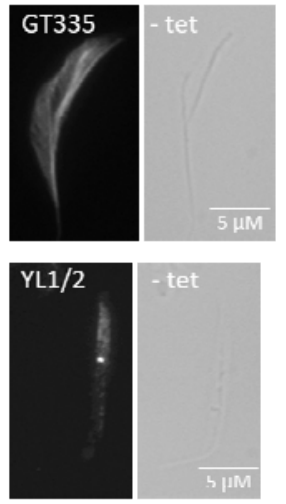

D

$3 d-3 d+4 d-4 d+5 d-5 d+$

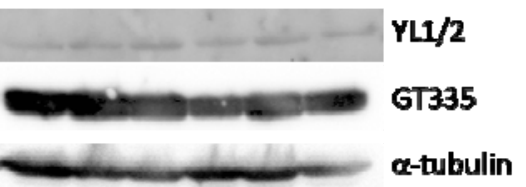

